\title{
Cellular Transplantation Strategies for Spinal Cord Injury and Translational Neurobiology
}

\author{
Paul J. Reier \\ College of Medicine and McKnight Brain Institute, University of Florida, Gainesville, Florida 32610
}

\begin{abstract}
Summary: Basic science advances in spinal cord injury and regeneration research have led to a variety of novel experimental therapeutics designed to promote functionally effective axonal regrowth and sprouting. Among these interventions are cell-based approaches involving transplantation of neural and non-neural tissue elements that have potential for restoring damaged neural pathways or reconstructing intraspinal synaptic circuitries by either regeneration or neuronal/glial replacement. Notably, some of these strategies (e.g., grafts of peripheral nerve tissue, olfactory ensheathing glia, activated macrophages, marrow stromal cells, myelin-forming oligodendrocyte precursors or stem cells, and fetal spinal cord tissue) have already been translated to the clinical arena, whereas others have imminent likelihood of bench-to-bedside application. Although this progress has generated considerable enthusiasm about treating what once was thought to be a
\end{abstract}

totally incurable condition, there are many issues to be considered relative to treatment safety and efficacy. The following review reflects on different experimental applications of intraspinal transplantation with consideration of the underlying pathological, pathophysiological, functional, and neuroplastic responses to spinal trauma that such treatments may target along with related issues of procedural and biological safety. The discussion then moves to an overview of ongoing and completed clinical trials to date. The pros and cons of these endeavors are considered, as well as what has been learned from them. Attention is primarily directed at preclinical animal modeling and the importance of patterning clinical trials, as much as possible, according to laboratory experiences. Key Words: Cellular replacement, clinical applications, gray matter reconstruction, white matter repair, translational research.

\section{INTRODUCTION}

An international conference in the early $1980 \mathrm{~s}^{1}$ convened a diverse group of investigators to discuss the issue of spinal cord pathology, reconstruction, regeneration, and plasticity. Although it was not the first scientific meeting addressing these and related topics, it was relatively unique in its emphasis on spinal cord repair and cell-based approaches, especially when only a modicum of previous scientific support for such an intervention existed. $^{2}$ A central theme then, as it remains, ${ }^{3}$ was the concept of bridging the lesion gap by providing a cellular terrain that would ideally promote and be amenable to axonal regrowth. The biological significance of Schwann cells was already well recognized from the pioneering studies of Tello and Ramon y Cajal. ${ }^{4}$ CNS regeneration research was also gaining new impetus from the groundbreaking work of David and Aguayo, ${ }^{5}$ who demonstrated

Address correspondence and reprint requests to Paul J. Reier, Ph.D., Department of Neuroscience, McKnight Brain Institute, University of Florida College of Medicine, Box 100244, Gainesville, FL 32610. E-mail: reier@mbi.ufl.edu. unprecedented long-distance axonal outgrowth from intrinsic CNS neurons when presented with a peripheral nervous system (PNS) tissue microenvironment. The use of embryonic CNS tissue in experimental studies of neurological disorders-especially Parkinson's disease (PD) — was likewise capturing attention at the time, and initial efforts had already been made using fetal brainstem cells to replace lost catecholaminergic inputs below complete transections of the spinal cord. ${ }^{6,7}$

In the two decades since that meeting, numerous advances have been made, leading to a greater collective understanding of the cellular and molecular biology of acute and chronic spinal cord trauma. ${ }^{3,8}$ In addition, spinal lesion models have become more sophisticated relative to reproducibility, behavioral analysis, and the structural-functional underpinnings of various sensory, motor, and autonomic consequences of spinal cord injury (SCI). ${ }^{9-12}$ Particularly notable has been the development of reproducible spinal cord contusion injuries ${ }^{13-16}$ that provide a close experimental approximation to a prevalent form of human SCI. ${ }^{17-19}$

This progress has made the breadth and complexity of 
spinal cord repair increasingly self-evident, and it is now fully recognized that a proverbial magic bullet cure is unlikely. Future treatments will undoubtedly involve a synthesis of complementary approaches, ${ }^{20-22}$ and many combination therapies will more than likely incorporate common modalities. Neurotransplantation could easily represent one such universal therapeutic component, and the intent of this article is to provide an overview of various facets of spinal cord repair that are integral to cellular transplantation/replacement approaches. In light of a growing emphasis on translational neurobiology and $\mathrm{SCI}$, the first half of this discussion will address some preclinical issues that warrant consideration as future investigations in humans are being envisioned. The remainder of this article will be devoted to a synopsis of past and ongoing clinical trials involving cell-based strategies. Recognizing that there have been many recent reviews of these topics, ${ }^{3,23-31}$ the following discussion is neither intended to repeat what has been already stated nor provide a fully inclusive literature review. Instead, the goal is to distill a large volume of information addressing various issues and rationales regarding the past, present, and future of cellular therapies for SCI and what has been learned from clinical experiences thus far.

A signature feature of this article is its emphasis on theoretical and practical risks/benefits that must be factored into the evolution of rational bench-to-bedside SCI experiences. Some of the considerations build on translational guidelines recommended by the American Society for Neurotransplantation and Repair Practice Committee. ${ }^{32}$ Previous elegant discussions regarding the advance of cellular therapies for other CNS disorders ${ }^{33,34}$ have also served as invaluable templates for this presentation.

\section{GOALS AND CHALLENGES OF APPLIED SCI RESEARCH}

Cell-based approaches that have the most imminent translational potential for spinal cord functional repair center on two fundamental directions that are not mutually exclusive: restitution of white matter long-tracts (to be referred to as "regenerative" approaches) and cellular (i.e., neuronal or oligodendrocyte) replacement. A cursory review of some basic aspects of the pathology, pathophysiology, and functional outcomes of clinical SCI is presented below to establish an immediate frame of reference for the anatomical setting in which cellular transplantation therapies would be used, along with some rationales and challenges that may govern the evolution and ultimate clinical goals of bench-to-bedside initiatives.

\section{General features of SCI}

As reflected by many SCI reviews, ${ }^{3,35-46}$ a variety of histopathological profiles are exhibited in humans after spinal trauma that ranges from a solid cord injury with disrupted white matter and no concomitant necrosis of central gray matter, to massive laceration/penetrating injuries causing the obliteration of recognizable anatomical features and the formation of a dense fibrotic scar at the lesion epicenter. A somewhat intermediate spinal insult is the contusion injury, which has as high as a $50 \%$ incidence and represents the most frequently used clinically relevant injury model in acute and chronic SCI research.

Initially, contusion of the spinal cord leads to local mechanical tissue damage, resulting in cellular necrosis. Soon thereafter, a series of catastrophic pathophysiological and neuropathological events ensue, which result in the progressive, secondary (i.e., bystander) demise of both gray and white matter. ${ }^{47}$ With the advent of microarray analysis, the transcriptome complexity of postSCI pathophysiological sequelae is becoming increasingly apparent, ${ }^{48-53}$ and secondary tissue loss is unlikely to be attributable to any single event, but instead the result of additive or converging biochemical/molecular, vascular, and inflammatory processes. ${ }^{38}$

\section{White matter damage: not all is lost}

In a worst-case scenario, a severe contusive insult can lead to complete tissue destruction at the lesion epicenter analogous in certain respects to a total transection. Such anatomically complete lesions, however, are uncommon. ${ }^{35,46}$ Injuries of lesser magnitude are more frequent and typically display end-stage features characterized by central hemorrhagic necrosis of gray matter with concomitant neuronal loss and the formation of fluid-filled cysts. In addition to primary necrosis and advancing secondary demise of neurons and many white matter tracts, widespread oligodendrocyte apoptosis also occurs at the epicenter and significant distances rostral and caudal to it. ${ }^{47,54-61}$ Despite such widespread degeneration, a consistent feature of the injury epicenter in many SCI cases is the presence of varying amounts of preserved white matter that may be as little as a thin subpial rim of preserved axons (FIGS. 1a,c, and 2a) in more severe injury conditions. ${ }^{62}$ Many of these fibers, however, may become demyelinated ${ }^{63}$ as a basic aftermath of the initial post-SCI inflammatory response and oligodendrocyte apoptosis just noted and may exhibit progressive stages of remyelination at later postinjury intervals (FIG. 1b,d). By rendering spared axons dysfunctional, this form of primary demyelination is thought to account for some longterm deficits resulting from SCI.

Partial white matter sparing has fundamental implications relative to the choice of a cell-based repair strategy that can vary from one individual to another. According to criteria established by the American Spinal Injury Association (ASIA), SCI cases can be classified as functionally "complete," i.e., no sensory or motor function below the level of injury (at sacral levels $\mathrm{S}_{4}-\mathrm{S}_{5}$; ASIA 


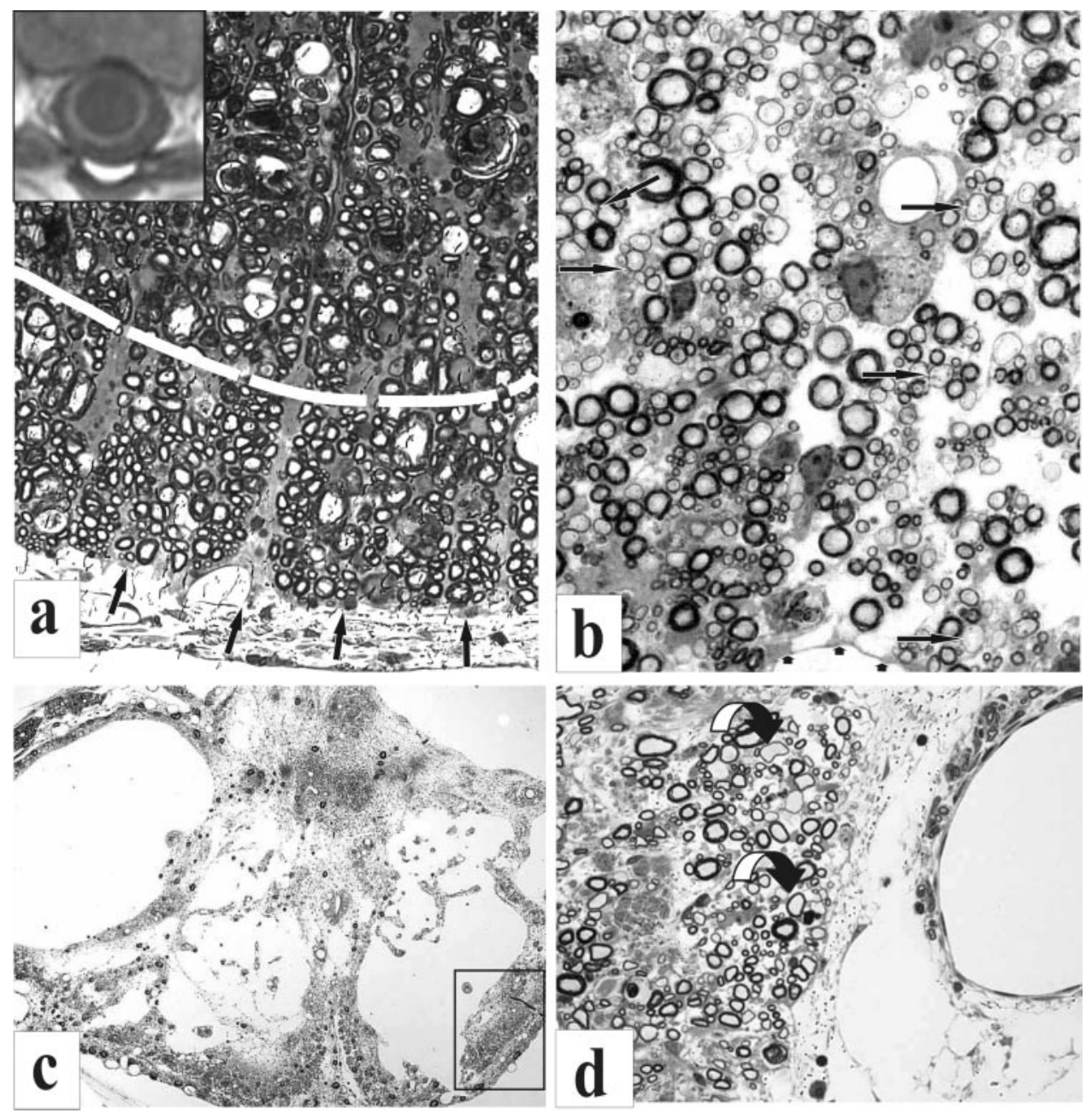

FIG. 1. a-d: Partial preservation of myelinated fibers is illustrated in plastic semithin sections and a MR transverse slice obtained from a human subject (a, inset). a: A region of ventrolateral white matter is shown at a contusion epicenter site 3 weeks postinjury in an adult rat spinal cord. This region is subdivided (dashed white line) into a more centrally located zone that is undergoing extensive fiber degeneration and a more peripheral region (pial surface indicated by arrows), in which a rim of some spared fibers is seen. A more severe injury is illustrated in c. In this transverse section of the lesion epicenter of an adult cat spinal cord, as seen 4 months after a static load compression injury, nearly all of the spinal cord has deteriorated except for regions in which a few axons are present subjacent to the surrounding pia. The boxed area represents one such fiber zone that is shown at higher magnification in $\mathrm{d}$. In regions of spared white matter ( $b$ and $d)$, there can be extensive demyelination and remyelination noted (arrows point to some examples). These regions also may appear less compacted because of associated fiber loss and edema. The MR image (inset) shows a human correlate of what is illustrated in histological sections. A rim of white matter can be identified surrounding a large central cyst at T5. Preop, preoperative.

"A"), or functionally "incomplete" (ASIA "B," "C," or "D"), with ASIA "E" being normal. Today, over 55\% of SCI cases are designated as being incomplete. This status can be explained in terms of tissue sparing, but it does not automatically infer that functionally complete injuries are anatomically complete, ${ }^{43}$ and thus a priori more uniformly dependent on axonal regeneration to reunite separated spinal cord segments. Generally speaking, individuals with functionally incomplete and some with complete injuries could thus equally impose less demands on a given therapeutic approach. Therefore, although the goal of SCI research is usually directed at large-scale, long-distance regeneration per se, this may not be a universally obligatory requirement because of partial sparing of ascending and descending white matter systems in many cases. ${ }^{64,65}$ Undoubtedly, it would be ideal to have adjunct pharmacological, imaging, and neurophysiological protocols available to define the most rational therapeutic approach required on a patient-bypatient basis.

A closely related issue is: how much regeneration should be sought? In animals and humans with SCI, relatively significant functional preservation can be obtained with sparing of $\sim 10-15 \%$ of white matter. ${ }^{63,65,66}$ This has led to the suggestion that only a small degree of regeneration may be required to restore meaningful function. ${ }^{67}$ It should be emphasized, however, that functional sparing associated with intact fiber systems is not necessarily equivalent to functional restoration via regeneration and the re-establishment of appropriate synaptic 


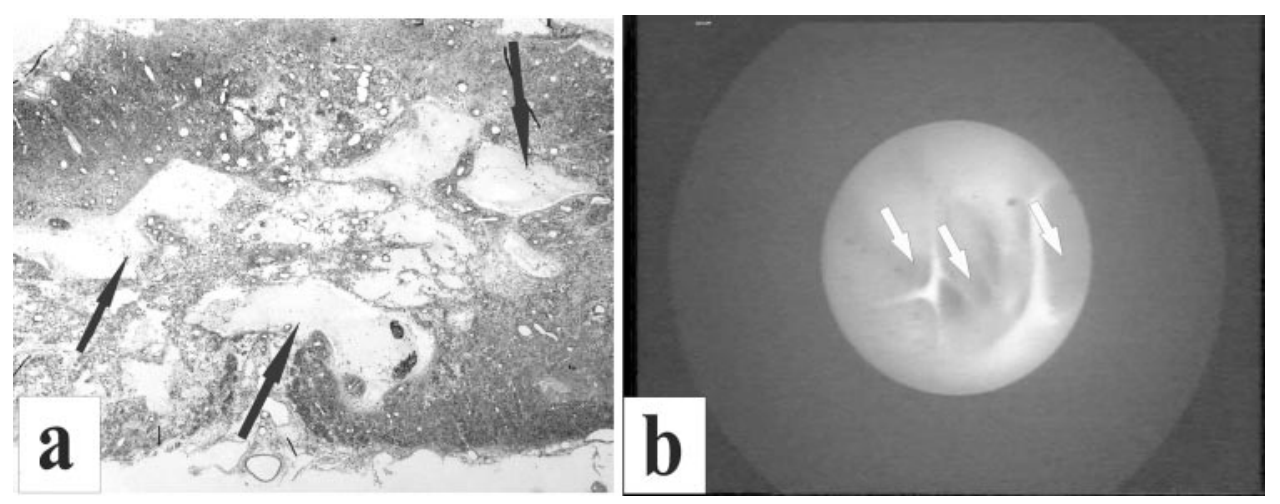

FIG. 2. a: A plastic semithin section, showing in transverse plane a static-load compression epicenter site in an adult cat spinal cord. A central region of highly partitioned cystic cavitation is indicated by arrows. The shell of surrounding "preserved" white matter has features similar to those shown in Figure 1, a and b. b: A "living" correlate of this image is seen in this syringoscopic view of a highly compartmentalized cyst (arrows) in a patient during an exploratory phase of intraspinal surgery (courtesy of Drs. Edward Wirth III and Richard Fessler).

relationships. On the other hand, as frequently noted, an overly robust regenerative response to an intervention may have adverse consequences.

\section{Some risks of regenerative or restorative white matter repair}

Procedural and biological safety issues are clearly paramount in the design of any clinical trial. ${ }^{68}$ The presence of spared axons after most cases of SCI bears heavily on the issue of risk/benefits, and the potentially inconsistent relationship between anatomical and functional completeness must be carefully weighed into the design and rationale for any invasive therapeutic spinal cord repair procedure. Paradoxically, axonal sparing presents a logistical dilemma that is difficult to dismiss. On one hand, the more axons spared, the greater the potential risks of additional injury using an intraspinal surgical procedure. At the same time, having more spared fibers offers greater potential for achieving significant functional improvements. ${ }^{69}$ Endoscopic microneurosurgery (FIG. 2b) ${ }^{70}$ which is still in its infancy, and preoperative neuroprotection may thus become important adjuncts to intraspinal transplantation. ${ }^{71}$ Discussions at recent meetings have also raised the issue of how an individual's participation in one trial may later affect chances of enrollment in others. Therefore, what must be kept in mind at the very least is that any inadvertent, intraoperative damage could diminish the opportunity for potential gains from newer generation and more efficacious interventions should initial trial outcomes be suboptimal.

\section{Neuronal replacement in the injured spinal cord}

In contrast with axonal regeneration and/or remyelination of spared axons, the rationale for neuronal replacement in the injured spinal cord is less defined and infrequently articulated. This is especially ironic in light of many lay and scientific articles on stem cells and neuronal restoration, which frequently cite SCI as one of many neurological targets. Even when the field of fetal CNS tissue transplantation was beginning to burgeon, few investigators were focused on SCI. The objective of using embryonic cells to replace a specific neurotransmitter phenotype, as discussed by Lindvall and Björklund in this issue of NeuroRx ${ }^{\circledR}(1: 382-393,2004)$, seemed far more feasible than reconstruction of complex neural circuitries, although this was an early stated goal of neurotransplantation research. ${ }^{72}$

With regard to SCI, many aspects of intraspinal circuitry remain poorly understood in terms of their functional cytoarchitecture. For example, how does one reconstruct a spinal central pattern generator (CPG); what are the specific neuronal phenotypes and synaptic interactions required? The potential importance of neuronal replacement has also been masked because SCI has been frequently regarded as primarily a "white matter" problem, based on some issues discussed above and other lines of evidence. ${ }^{73,74}$ Even substantial loss of gray matter after SCI, except at specific spinal cord levels, has been considered to be of relatively little consequence. ${ }^{36,74}$

This emphasis on white matter, however, derives primarily from the predominant use of thoracic SCI models and the prevailing focus on hindlimb motor function. ${ }^{10,75}$ For instance, discrete, excitotoxic lesions in the thoracic spinal cord, which destroy central gray matter without affecting surrounding long-tract systems, appear to have no consequence on hindlimb locomotion in the rat. ${ }^{76}$. It is conceivable, however, that thoracic lesions could in the meantime affect axial musculature and posture; the same may be true for cervical spinal injuries. ${ }^{77,78}$ Recent studies in which gray matter was pharmacologically rescued after a thoracic contusion injury showed an increase in the control of trunk musculature, although.hindlimb locomotion did not improve. ${ }^{79,80}$ From a clinical rehabilitative perspective, axial musculature stability is vital.

Similarly, other studies have indicated that central gray destruction alone can lead to enhanced tonic and driven 
discharges of spinal neurons bordering a central gray lesion. ${ }^{81}$ Local circuit changes in GABA could account for allodynia after $\mathrm{SCI}^{82}$ as a result of decreased inhibitory tone in the injured cord and an increased excitability of spinal neurons. ${ }^{83}$ Even small lesions of spinal gray matter can affect sensitivity to thermal input over segments remote from the lesion. ${ }^{84}$ Interestingly, a thoracic level $8\left(\mathrm{Th}_{8}\right)$ contusion injury can lead to chronic pain manifestations in a rat that are similar to those seen in human SCI, whereas hemisections at that level do not result in the same profile. ${ }^{85}$ This may entail damage to a spinal gray-ventrolateral quadrant system that transmits nociceptive information from cutaneous body regions. Midthoracic chronic SCI also can elicit sexual dysfunction in both rats and humans, and this could involve a spinal gray-dorsolateral quadrant system conveying nociceptive information from mucocutaneous/pelvic/visceral territories. ${ }^{86}$

In contrast to thoracic injuries, it is easier to envision gray matter repair relative to lesions at cervical or thoracolumbar/lumbar levels. Motoneuron replacement is an immediately obvious consideration, although the columnar organization of motoneuron pools over several segments of the spinal cord in many instances (e.g., McKenna et al. $^{87}$ ) and peripheral collateral sprouting as well, ${ }^{88}$ can contribute to preservation of sufficient neuromuscular integrity. Thus, deficits may not be apparent except under demanding conditions, as exemplified in the case of respiratory function after midcervical SCI (FIG. 3).

A more intriguing, yet challenging, cell therapy target would be replacement of interneurons, ${ }^{89}$ including longprojecting and short-projecting propriospinal neurons (PSNs). Descending suprasegmental systems frequently terminate on interneurons rather than make direct monosynaptic connections onto motoneurons. Interneurons assume even greater significance, such as in the case of the hindlimb CPG, which resides at spinal level $\mathrm{L}_{2}$ in the rat. Using the same excitotoxic lesion approach noted above, restricted gray matter deletion at spinal level $\mathrm{L}_{1}-\mathrm{L}_{2}$ results in hindlimb locomotor deficits equivalent to those produced by severe thoracic spinal contusion injuries 76,90 . No correlation with motoneuron loss was observed in those experiments, thus underscoring the importance of regional interneuronal excitotoxin-induced depletion.

The negligible behavioral consequences attributed to gray matter loss to date are rather paradoxical, because quantitative studies have estimated that in some regions of the spinal cord, as much as $60 \%$ of the fibers are of propriospinal origin. ${ }^{91}$ Concerning recovered hindlimb activity, neuroanatomical studies of spared axons after mild or moderate contusion injuries have suggested that propriospinal projections play little or no role. ${ }^{69,92}$ From another perspective, however, it is well known that PSNs originating at spinal level $\mathrm{C}_{3}-\mathrm{C}_{5}$ send long projections to

\section{EMG Amplitudes During Augmented Breaths $\mathrm{C}_{4-5}$ Contusion Injury}

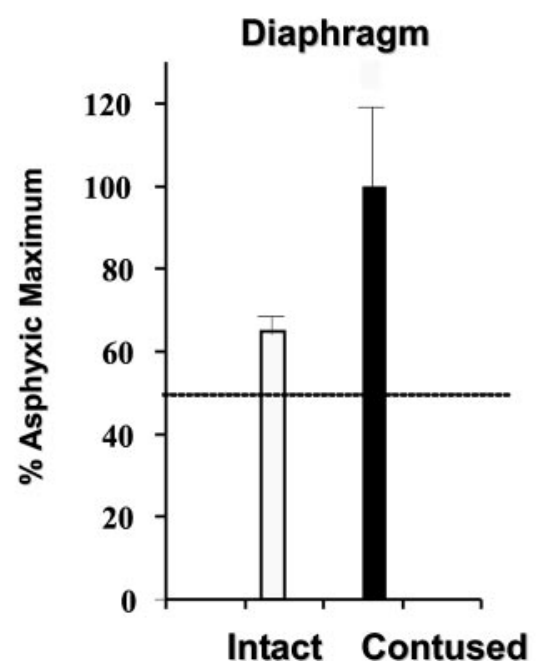

FIG. 3. Motoneuron loss after a spinal injury may not exhibit profound clinical symptoms except under more demanding conditions. This figure illustrates phrenic motoneuron pool (i.e., $\mathrm{C}_{3}-$ $\mathrm{C}_{5}$ ) utilization in adult rats as exemplified by diaphragm EMG amplitudes during augmented breaths (i.e., equivalent to a sigh). Under normal breathing conditions, only $50 \%$ of the phrenic motoneuron pool is used (dashed line); however, when augmented breathing is induced, rats will recruit an additional 10$20 \%$ of available phrenic motoneurons. After $\mathrm{a} \mathrm{C}_{4}-\mathrm{C}_{5}$ contusion injury, respiratory function is not overtly different from that seen in controls under normal conditions. However, when faced with respiratory challenge, those animals recruit virtually all of the remaining phrenic motoneuron pool (data obtained in collaboration with Dr. Donald Bolser). Thus, from a human perspective, even when a cervically injured individual may not require ventilatory assistance, respiratory performance is severely compromised, thus leading to respiratory weakness evident, for example, in speech or cough.

the lumbosacral enlargement and are intimately involved in forelimb-hindlimb coordination. Other evidence indicates that even local, short-distance commissural PSNs are important components of the spinal locomotor network. ${ }^{89}$ Such cells have significant input on nearby motoneurons and mediate hindlimb functional recovery. ${ }^{66,93,94}$ For example, $\mathrm{C}_{3}-\mathrm{C}_{4}$ PSNs in the cat project monosynaptically onto motoneurons, la inhibitory interneurons, and spinoreticular and spinocerebellar neurons at the forelimb segments of $\mathrm{C}_{6}-\mathrm{Th}_{1}{ }^{95}$. These cells receive converging cortical and brainstem projections and mediate the command for visually guided target-reaching movements and conjoint control of axial muscles to stabilize the trunk during target reaching. ${ }^{96}$ Given the vulnerability of PSNs to many forms of SCI, possible replacement of these cells is conceptually intriguing, especially because long PSN projections also have the potential to serve as a functional relay between hindlimb corticospinal tract axons rostral to an injury and caudal, lumbar motoneurons. ${ }^{97}$ Studies of lower vertebrates (e.g., lampreys ${ }^{98,99}$ ) also suggest that lesions affecting short PSN projections, thereby interrupting a cascade of 
intersegmental coupling, could contribute to some functional consequences (e.g., such as increased neuronal excitability as noted above) that are masked by the more obvious motor deficits caused by damage to supraspinal systems. Therefore, although at face value gray matter destruction may not appear to have much consequence on function, restoration of spinal gray matter continuity may prove more vital to the overall recovery process than presently recognized.

\section{FUNCTIONAL OUTCOME TARGETS FOR CELL-BASED STRATEGIES}

In contrast with other CNS disorders that have been addressed using cellular interventions (e.g., PD and Huntington's disease), the neurological conditions associated with SCI are more variable, multimodal, and subject to different degrees of spontaneous improvement over time. $^{42,100}$ In that context, the extent of primary and secondary tissue damage, degree and type(s) of functional disability, and the extent of possible recovery after a spinal cord contusion are dependent on the spinal level and severity of the injury. Approximately 55\% of SCI cases occur in the cervical spine region (predominantly $\mathrm{C}_{4}-\mathrm{C}_{5}$ ), whereas the remaining $45 \%$ are evenly distributed between thoracic, thoracolumbar, and lumbosacral levels. ${ }^{101}$ Aside from motor deficits associated with tetraplegia or paraplegia, individuals who have sustained spinal cord trauma must often deal with other associated neurological maladies, such as loss of sensation, decubitus ulcers, chronic pain, spasticity, bowel/bladder dysfunction, and compromised sexual function. High cervical (i.e., $\mathrm{C}_{2}$ ) injury can lead to temporary or permanent loss of diaphragm function, and even lower cervical injuries may contribute to significant respiratory insufficiency. A less often cited, yet physiologically important, consequence of cervical and thoracic injuries (above $\mathrm{Th}_{7}$ ) is a diminished cough reflex, which involves coordinated activity between abdominal muscle and the phrenic motoneuron $(\mathrm{PhMN})$ pools at the $\mathrm{C}_{3}-\mathrm{C}_{5}$ spinal cord levels. ${ }^{102}$ This alone can contribute to a higher propensity for pneumonia. In that regard, a simple cold could become a major health setback, if not ultimately a life-threatening risk, for some individuals with SCI. Another potentially life-threatening condition, autonomic dysreflexia, occurs in 50-90\% of individuals with tetraplegia or high paraplegia (involvement of the sympathetic nervous system contained within the thoracic spinal cord). This condition entails evoked hypertension in response to noxious sensory inputs below the level of injury that can be manifested in acute ${ }^{103}$ and chronic ${ }^{104}$ SCI. Some evidence suggests that chronic pain may be an associated condition. ${ }^{105}$

This cursory overview of the multimodal consequences of SCI underscores the daunting complexity confronting cellular and other therapeutic approaches. Although restoration of the ability to walk is a commonly expressed scientific and clinical goal, there are many other dysfunctions resulting from SCI that, if corrected, could translate into significant improvements in the quality of life.

In many respects, meaningful functional spinal cord repair may not be as heroic an effort as it would seem given what substantive improvements can be genuinely sought. ${ }^{42,43}$ Functional repair over a distance of as little as one cervical spinal segment (e.g., $\mathrm{C}_{2}-\mathrm{C}_{3}$, for unassisted respiration, or $\mathrm{C}_{6}-\mathrm{C}_{7}$, for triceps function) could represent a profound difference in independence. Likewise, attenuation of spasticity, autonomic dysreflexia, or chronic pain would be of tremendous relief to most individuals with SCI. ${ }^{75}$ Similarly, restoration of bowel and bladder control or improvement in sexual function would have tremendous health and psychosocial benefits. Individually or in some combination, these post-SCI outcomes represent realistic goals, and functional repair may be less demanding for some aspects of SCI than others. Furthermore, incremental improvements can constitute significant patient benefits. For that reason, it has become increasingly imperative to establish reliable animal models for these conditions in conjunction with the development of rigorous, quantifiable outcome measures for both experimental and clinical purposes. ${ }^{23}$

\section{HIPPOCRATES AND SPINAL CORD PLASTICITY}

Because the cervical spine is a frequent site of SCI, as well as the region that can most benefit from an intervention over minimal distances, biological and procedural safety (i.e., intramedullary approaches not routinely used in spinal surgery) both assume obvious and paramount importance, as noted earlier. This leads to the question: "which level of the spinal cord and postinjury neurological disposition represents the safest subject profile for early clinical trials"? ?3,106-108 One consideration has been stable, motor complete thoracic injuries; however, even at that level, potential risk to a spared cough reflex, for example, cannot be casually dismissed, depending on the specific thoracic region involved and the degree of anatomical disruption. In many respects, there is no innocuous spinal level. Therefore, preclinical studies in which procedural and biological safety are rigorously tested have as much scientific importance, if not more, as other investigations exploring treatment efficacy and underlying mechanisms. Apart from the possibility of exacerbating existing deficits, the risk of inducing pain represents another commonly expressed concern.

Beyond "doing no harm," however, safety also embodies another level of significance related to the self- 


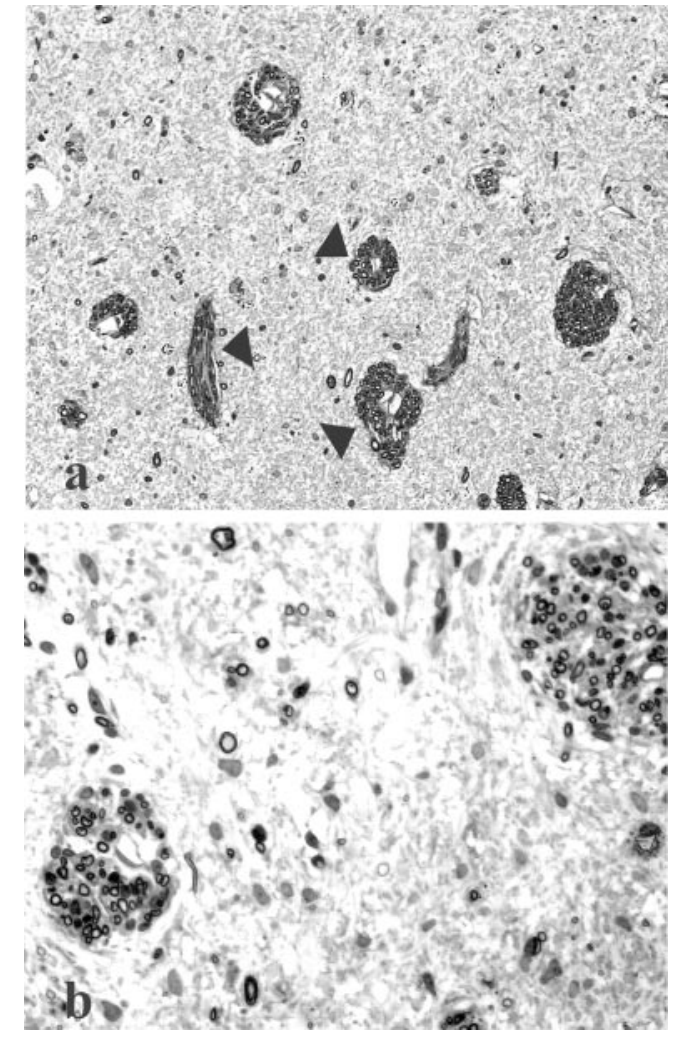

FIG. 4. Extensive white matter damage is seen in these micrographs taken from the epicenter of a static load compression injury to an adult cat spinal cord. Months after that injury, the white matter is replaced by an amorphic cellular terrain in which large fascicular structures are seen (a). At a higher magnification (b), these structures are bundles of axons that are myelinated by Schwann cells. Some individual fibers are seen in the surrounding tissue parenchyma. As discussed in the accompanying text, Schwann cell infiltration of the injured spinal cord is a common feature in animals and humans and represents one form of potential self-repair that can be augmented by grafts of Schwann cells and other cell types (e.g., olfactory ensheathing glia).

repair capacity of the spinal cord (i.e., functional plasticity). Ideally, an intervention should not adversely affect favorable intrinsic restorative mechanisms, but instead should amplify or be enhanced by them. Although earlier studies of spared dorsal root preparations provided compelling examples of the potential for intraspinal anatomical and functional plasticity, ${ }^{109}$ the capacity of the spinal cord for recruiting compensatory function was not fully appreciated. There is growing recognition, however, of the existence of intrinsic repair processes, ${ }^{110,111}$ some of which may entail the same tissue framework (FIG. 4a,b) on which potential cellular therapies have been based. ${ }^{112,113}$ Likewise, several functionally positive neuroplastic changes at segmental and suprasegmental levels have been reported in individuals with chronic SCI. ${ }^{65,114}$ Experimental evidence suggests that even a few spared axons in contusion injury models may influence reorganization of circuits and enhanced motor output below the level of injury. ${ }^{69}$ It is well established that the respiratory ${ }^{115-118}$ and reproductive ${ }^{119}$ centers of the spinal cord exhibit remarkable degrees of intrinsic functional and anatomical plasticity, which is seen in many species, including humans. Functional recruitment of redundant pathways, as discussed below, represents another significant example of spinal cord plasticity.

\section{WHAT LONG-TRACT SYSTEMS SHOULD BE TARGETED BY REGENERATIVE OR CELLULAR REPLACEMENT THERAPIES?}

Given the neuroplastic potential of the mammalian spinal cord, it is understandable that definitive conclusions remain elusive about anatomical-functional relationships after SCI, especially in animal models of contusion injury. ${ }^{69}$ Similarly, there are many clinical examples in which it is difficult to make direct and prognostic correlations between regions of compromised white matter integrity and early or chronic functional outcomes. Neuroanatomical studies that have examined the origins of spared axons after mild and moderate contusion injury in rats have shown varying degrees of sparing of hindlimb locomotion-associated and brainstem-descending systems. Significant hindlimb function can thus still be present, although the relative amount of supraspinal input may differ. ${ }^{69,120-121}$ Sprouting of some damaged descending systems within the contusion epicenter has also been reported, ${ }^{122}$ which could lend to cellular repair strategies.

Such observations further underscore compensatory/ neuroplastic possibilities upstream and downstream from a spinal injury. ${ }^{65}$ Post-traumatic syringomyelia (PTS), reviewed in Wirth et al. ${ }^{123}$ is one type of a spinal injury condition in which examples of robust neuroplasticity potential of the human spinal cord can be seen. This condition is characterized by a progressive expansion of cystic cavitation resulting from the original injury. The ascending advance of associated myelomalacia is symptomatic and can entail intractable pain and gradual functional loss above the level of injury. As described previously, ${ }^{29,74}$ however, despite the extreme gray matter pathology of PTS because of significant loss of interneurons and white matter, relatively minimal clinical deficits are manifested in some individuals. The slower pace of PTS development appears to provide sufficient opportunity for anatomical and functional reorganization that effectively masks the otherwise significant deterioration of spinal cord tissue that often occurs.

A consensus is that ventral white matter is vital to spared or restored locomotor capabilities. However, others $^{124}$ have suggested that locomotion can be triggered by a variety of descending systems that reveal a significant degree of functional redundancy and diffuse axonal distribution within ventral pathways. ${ }^{125}$ Other data suggest that injury of dorsolateral funiculus fibers in the rat 
thoracic spinal cord may contribute to locomotor deficits, but only when there is simultaneous compromise of axons in the ventrolateral funiculus. ${ }^{126}$ Meanwhile, other investigations showed that selective lesions of the cervical dorsal column and/or dorsolateral funiculus led to altered locomotor capacities and ipsilateral forelimb impairments during specific behavioral tasks. ${ }^{76,127,128}$ Functional plasticity/redundancy in spinal white matter was also effectively demonstrated in a series of papers by Alstermark and colleagues, ${ }^{129-131}$ who showed in cats that multiple descending pathways subserved complex forelimb functions via $\mathrm{C}_{3}-\mathrm{C}_{5}$ PSNs. After a $\mathrm{C}_{5}$ transection, the ability to retrieve food with forepaws disappeared as a result of interruption of the corticospinal and rubrospinal tracts, which normally mediate this function. However, over a period of months, some recovery occurred as bulbospinal fibers were gradually recruited into this behavior. ${ }^{95}$

Although additional discussion of the contributions of various fiber systems at different spinal levels is beyond the scope of this article, it should be noted that selective lesion experiments, such as the ones cited, do not involve the same conditions as those encountered after more clinically relevant injuries in which different cues may influence functional expression by spared axons. ${ }^{125}$ Furthermore, the considerable emphasis on descending systems after SCI often overlooks the important role ascending systems play in locomotor function and other behaviors, ${ }^{76}$ such as male reproductive function, ${ }^{85}$ among other well known somatosensory modalities that they subserve.

\section{CLINICAL EXPERIENCES WITH REGENERATIVE SCI CELLULAR REPAIR STRATEGIES}

Although translational approaches in cell-mediated repair of the injured spinal cord are now a major topic of interest, it should be appreciated that intraspinal neurotransplantation in humans is not a novel endeavor. One bizarre anecdotal example is a case reported 60 years ago (cited from the introductory chapter in Sladek and Gash $^{132}$ ), in which an adolescent male SCI patient was the recipient of cadaveric adult spinal cord tissue that had been previously fixed in formalin, rinsed in distilled water, and then stored in $70 \%$ ethanol. ${ }^{133}$ Although this is an exceptional case, there are a few experimental procedures now being done on human subjects that, in terms of supporting rationale and preclinical scientific documentation, are as ill-founded. A notable example is that of the transplantation of embryonic shark cells, which was initiated in 1991 in Tijuana, Mexico and is apparently still being pursued. Short of website descriptions (http://www.electriciti.com/spinal/treat.htm) indicating a multifactorial approach in which the basis for any purported recovery is impossible to discern, there is no peer-reviewed documentation available of this procedure or its outcomes, and the founding rationale is seemingly unsubstantiated. Even more disappointing, however, is that no validated information is available regarding procedural, much less biological safety, because from that perspective some worthwhile information could be salvaged from these efforts. Because there is no apparent reason to otherwise question the neurosurgical skills of the clinicians involved, it is conceivable that some other very useful information could be obtained from that experience, especially if bona fide favorable outcomes could be substantiated either in terms of the surgery or adjunct rehabilitative therapies used.

A variety of donor cell types have been and continue to be the focus of laboratory studies directed at spinal cord functional repair via regeneration/sprouting, remyelination, neuronal replacement, and cell-mediated neuroprotection. One investigation involving human fetal spinal cord tissue transplantation has already been used in completed clinical studies reported in peer-reviewed journals (referenced below), whereas the applications of others are still under investigation. The following will provide a capsule description of some finalized or inprogress clinical studies and a selective summary of supporting experimental evidence. It should be noted that everything described is based either on published reports, presentations at meetings that were not under the aegis of confidential information, or selective website searches. Also, other approaches, such as genetically modified cells, ${ }^{134}$ which have not yet been tested on SCI subjects, are not discussed, despite their future translational likelihood.

\section{Regenerative repair of the injured spinal cord: peripheral nerve tissue}

Preclinical foundation. Varieties of cell types and grafting platforms have been studied because of their considerable potential for promoting axonal regeneration. In the case of Schwann cells (SCs) and olfactory ensheathing cells (OECs), these glial elements have a dual capacity for stimulating fiber regrowth as well as remyelination. Emphasis here will be on their regeneration-promoting properties.

The experimental evidence suggesting potential clinical applications of peripheral nerve (PN) tissue or highly enriched preparations of Schwann cells is well established in the literature. ${ }^{43,135-137}$ To summarize, SCs have neurotrophic, ECM, and cell adhesion properties that are favorable to axonal regeneration in the peripheral nervous system. ${ }^{138-139}$ Numerous studies also have shown that grafts of PN tissue can induce and support axonal outgrowth over long distances from CNS neuronal populations in the brain, optic nerve, or spinal cord. ${ }^{140,141}$ It is even possible to harvest human SCs and establish large 
numbers of them in high purity in tissue culture ${ }^{142-144}$ for subsequent autologous transplantation. ${ }^{145}$ In addition, SCs lend well to genetic modification and are thus useful cellular vehicles for ex vivo gene delivery and other combination therapies. ${ }^{145-147}$

One of the more contemporary applications of PN tissue/cell grafts in SCI was performed by Kao and colleagues ${ }^{148-150}$ using complete transections, as well as spinal compression injury models in rats and cats. Thereafter, many studies of PN or SC-mediated axonal regeneration in the injured spinal cord were reported by other laboratories. ${ }^{135,151-162}$ Interestingly, some descriptions of rodent and human SCI have indicated that large numbers of SCs can gradually infiltrate a spinal lesion (i.e., schwannosis $^{35,163}$ ) and thereby facilitate some degree of spontaneous axonal growth. ${ }^{113}$

Clinical applications. This author is unaware of any documented human trials involving the transplantation of purified populations of SCs; however, there are various reports outside the realm of peer-reviewed journals of PN tissue grafts having been made in SCI patients worldwide, and some may still be in progress. Notably, Kao's last scientific report, as far as this author could trace, was at the 8th International Congress of Neurological Surgeons and based on 90 cases. ${ }^{164}$ It appears that many more operations that are similar have been performed by him since then (most recently in Ecuador) (http://www.oaoa.com/news/nw022502b.htm). Furthermore, some more recent surgeries may have been nerve bypasses in which functional motor pools above a lesion were being used to drive circuits caudal to the injury. If that is the case, valuable clinical information is being lost that directly relates to a recent study of a similar approach that in rats appeared to have significant results. ${ }^{165}$ The apparent benefits of the PN procedure attributed to Kao via internet accounts from former patients are difficult to assess because of other treatments that were applied in conjunction with the surgery. The most unfortunate situation once again is that important safety-related data are not available. Given the many potential complications that could be encountered at some spinal levels, it is impressive that there are no publicly recorded indications of significantly adverse outcomes from informal website postings.

More recently, Barros and colleagues, in Sao Paolo, Brazil (http://www.healingtherapies.info/WHO.htm) have grafted PN tissue into completely transected spinal cords, and the neurological risks discussed earlier appear to be minimal in such anatomically/functionally complete individuals. Apart from a recent abstract, ${ }^{166}$ no formal publications have materialized to date. It appears, however, that this investigation was conceptually in synchrony with some preclinical studies, and choices of outcome measures were reasonable. In certain respects, the subjects were the ideal candidates for an early clinical endeavor; at the same time, their neurological status challenges the potential for seeing any significant functional gains. The approach used by Barros is based partly on other surgical protocols, ${ }^{167-169}$ discussed below, that were reported to be very promising. Thus, sural nerve grafts were made in combination with the administration of FGF and the application of fibrin glue to ensure intimate apposition of PN tissue with apposed surfaces of the spinal cord. Postoperative evaluations involved ASIA/International Medical Society of Paraplegia standards, magnetic resonance (MR) imaging, and somatosensory-evoked potentials. Graft viability was observed after 30 months. Although there was no motor or sensory improvement, less spasticity was indicated in patients who had undergone this procedure.

In view of limited information, even the instructive value of these clinical PN grafting endeavors remains uncertain, although anticipated publication of the data obtained in the Sao Paolo study could provide some useful insights. There are some lines of evidence, however, that would strongly challenge whether any significant functional benefits could be expected using PN grafts alone. Few examples of functional improvements have been obtained experimentally with PN tissue grafts or SC populations to the CNS, although it is well known that axons growing within these grafts retain their physiological properties ${ }^{170}$ and can make functional synapses with neurons near their point of CNS re-entry. ${ }^{171}$ Axonal elongation after exiting PN grafts, however, is very limited in distance, as seen in rats, ${ }^{5}$ and more recently in subhuman primates. ${ }^{172}$ This is often attributed to the establishment of an inhibitory ${ }^{173,174}$ CNS-PNS transition zone-like configuration, ${ }^{175,176}$ in which peripheral nerve cells interface with astrocytes, as discussed in more detail below. A notable exception is a study in which multiple PN bridges were regionally interfaced at $\mathrm{Th}_{8}$ with white matter rostral to the injury and gray matter below. ${ }^{167}$ Postural and locomotor improvements were observed, and anterograde tracing studies showed regrowth of descending systems to lumbar levels. The reproducibility of this approach is still unclear, however, because at least two established SCI research centers were unable to replicate these findings (unpublished), whereas one other report has provided some corroboration. ${ }^{177}$

Two recent experiments are of interest relative to functional repair and PN tissue. In these studies, physiologically viable axons, either in a rerouted proximal motor nerve segment from $\mathrm{Th}_{13}{ }^{165}$ or in a PN bridge graft inserted rostrally into the respiratory center of the medulla, ${ }^{136}$ were directed to motoneuron pools (i.e., lumbar and phrenic, respectively) below the level of spinal injury. Both studies provided evidence for functional connectivity. In the case of the PN medulla-to-cervical bridge experiment, the findings clearly illustrated that regenerating respiratory axons retained their physiolog- 
ical properties and were able to establish stable and highly specific connections with an appropriate central target. These studies provide an important proof-of-concept, as well as a compelling illustration of the challenging complexity of spinal cord repair, even when some degree of functional regenerative potential is available.

\section{Regenerative repair of the injured spinal cord: olfactory ensheathing cells}

Preclinical foundation. Part of the difficulty in achieving greater functional connectivity with at least unmodified PN grafts alone centers on the cellular nature of the graft-host interface and the inhibitory molecular properties of the CNS. It has long been recognized that once fibers in PN or SC bridges re-enter the CNS, their elongation essentially comes to a halt. ${ }^{5,178,179}$ In general, SCs and PN tissue do not interact favorably with CNS elements, particularly astroglia. ${ }^{175,180-182}$ Thus, SCs often fail to become completely integrated within the CNS (for review, see Boyd et al. ${ }^{183}$ ), and there is experimental $^{182,184}$ and human clinical ${ }^{163}$ evidence suggesting that SCs may even promote gliosis and the deposition of nonpermissive ECM molecules, such as chondroitin sulfate proteoglycans, ${ }^{185-187}$ in which PN grafts and CNS cells intermingle. The challenge of achieving long-distance growth beyond the lesion becomes magnified by the presence of other CNS-related nonpermissive molecules. ${ }^{188,189}$ To circumvent this inhibitory milieu, trails of BDNF-expressing SCs were seeded over a distance of $5 \mathrm{~mm}$ below the site of complete spinal cord transections ${ }^{190}$ and shown to facilitate elongation to more caudal regions. Even under these conditions, the distance traveled by axons exiting the Schwann cell environment can be very limited ${ }^{191}$ unless the caudal interface is exposed to a neurotrophin cocktail ${ }^{192}$ or other ways to induce axonal growth ${ }^{193}$ are used.

Without cotreatments, however, the ideal cellular candidate for a cell-based repair strategy should thus be able to: 1) support axonal elongation and regrowth through the adult CNS, 2) restore myelin around spared axons having undergone primary demyelination, 3) freely migrate within the CNS parenchyma and coexist with astrocytes, and 4) fully integrate within the lesion microenvironment. ${ }^{194}$ Considerable attention has now shifted to OECs, a cell type with native properties that appear to fulfill these criteria. ${ }^{195-199}$ For experimental and ultimately clinical purposes, methods have been developed and are continuing to be refined to obtain purified and well characterized populations of these cells, which, like $\mathrm{SCs}$, can be prepared for autologous transplantation. ${ }^{194,195}$

The regeneration-promoting capacity of OECs has been explored under acute and chronic lesion conditions by several laboratories in completely or partially transected spinal cord models. ${ }^{198,200-203}$ In addition to the impressive regeneration-promoting attributes of OECs, ${ }^{204-206}$ functional improvements have been reported in overground locomotion ${ }^{200,207,208}$ as well as climbing and respiration. ${ }^{209 a, b}$ After extensive dorsal rhizotomies, these cells also facilitated regrowth of centrally directed sensory axons along with exhibiting some electrophysiological and behavioral indications of functional benefit. ${ }^{210}$ Likewise, OECs have been noted to restore axonal conduction after dorsal column lesions in rats. ${ }^{211,212}$ The ability of OECs to meld with astrocytes in vitro (reviewed in Barnett ${ }^{194}$ ) was subsequently corroborated by these and other in vivo studies. ${ }^{195,210,213-215}$ Although other differences have been since noted, ${ }^{216,217}$ the capacity of donor OECs to intimately interact with host astrocytes is the principal distinguishing feature between OECs and SCs.

Clinical applications of OECs. By seeming to surpass the regeneration-promoting properties of Schwann cells, the use of OECs in SCI has gained rapid and considerable momentum. One important prerequisite is to define the source of such autologous cells. This is not as straightforward as it may seem, because what is feasible in the rat is more problematic in humans. ${ }^{195,208}$ Inferences from the literature and open scientific discussions suggest that this issue has not been fully resolved. Nevertheless, clinical trials with OECs have proceeded in China, Portugal, ${ }^{218}$ and Australia. From informal accounts, over 400 people have undergone this procedure, with the majority having been done in China using olfactory bulbderived OECs from aborted fetuses. The only published account thus far, to this author's knowledge, describes some aspects of patient selection and early functional outcome data from 171 subjects who ranged from 2 to 64 years of age $^{219}$ and received the transplants at postinjury times extending as much as 30 years. Follow-up examinations were only performed up to 8 weeks after transplantation. Presently, no definitive conclusions can be drawn from this study based on experimental design and logistical issues. Investigators in Portugal (http://www.healingtherapies.info/ OlfactoryTissue1.htm) used a different component of the primary olfactory pathway as a source of OECs, and that study has focused on younger patients who are no more than 3 years beyond their injuries. Other web-based reports indicate that grafts of stem cell and OEC mixtures have also been performed on $\sim 15$ individuals with chronic SCI.

Commentary. Relative to the many unanswered basic science questions when these clinical trials were initiated and even now, ${ }^{195}$ it becomes a matter of individual conviction whether or not these endeavors were timely and justified in terms of risk/benefits (http://www.mcpf.org/ displayarticle.asp?articleId=115). For example, characterization of the cells needs to be improved and the methods of optimal delivery and numbers of cells required need to be determined as well. How to assess the degree to which these cells can survive in a human spinal 
cord is a major problem not limited to OEC grafting. Although some available functional data seems to be supportive, the extent of those preclinical evaluations is still extremely modest, and it is somewhat astonishing, given what little is presently known about these cells, ${ }^{183}$ that a rehabilitation center has announced the intent to evaluate patients for OEC transplantation procedures being done in Beijing and Portugal (http://www.sci-infopages.com/spinal-blog.html).

Whether continuation of such studies is appropriate becomes an even more immediate point of discussion unless enough information can be garnered from these first investigations. The fact that no harm has been experienced in clinical trials thus far does not in itself give license for additional pursuit. In addition, some recent preclinical functional outcomes in OEC-to-spinal cord grafting experiments require cautious interpretation. This especially applies to data suggesting OEC-mediated recovery of respiratory function, ${ }^{209 a}$ which are questionable because of many methodological concerns related to respiratory data procurement. Furthermore, the results obtained from control animals are in striking contrast to independently reproduced findings showing that some ipsilateral spontaneous phrenic function recovers between 1 and 2 months after a $\mathrm{C}_{2}$ hemisection in adult rats. ${ }^{116-118}$ It should be noted, however, that more recent independent evidence ${ }^{209 \mathrm{~b}}$ showed that OEC transplantation could contribute to substantial phrenic functional recovery ipsilateral to a $\mathrm{C} 2$ hemisection, although the mechanism by which this may occur is presently unknown.

Somewhat ironically, clinical trials were initiated before specific analysis of OECs was performed in a clinically relevant SCI model. Interestingly, a recent study ${ }^{216}$ in which the effects of cultured SCs and OECs were compared, alone or in combination, showed that SCs were more effective in promoting axonal regeneration/ sparing and remyelination in the contused spinal cord than OECs. OECs, however, seemed to facilitate axonal elongation at graft-host interfaces. These findings suggest that a combined SC-OEC grafting approach might be more beneficial in the contused spinal cord than one involving OECs alone, as ongoing clinical trials have pursued. It also has been found that delayed transplantation of OECs into a contusion injury is more effective in stimulating regeneration/sprouting of supraspinal axons than grafts made immediately after injury, but only modest hindlimb functional improvements were observed. $^{220}$

\section{Regenerative repair of the injured spinal cord: marrow stromal cells}

Preclinical observations. Bone marrow cells have been the subject of considerable interest in recent years, and initially attracted attention because of their stem cell-like attributes and pluripotency. ${ }^{221}$ In the neurosciences, these cells were particularly inviting for CNS repair because of their apparent ability to give rise to neurons and glia. ${ }^{222-225}$ Those findings, however, have not been corroborated ${ }^{226 a}$ and even subject to challenges based on issues pertaining to cell fusion and transdifferentiation, ${ }^{226 b, 227}$ and the absence of distinct neuronal morphological features and properties, despite their expression of some neuronal markers. ${ }^{228,229}$ Recent observations, ${ }^{230}$ however, showing that human hemopoietic cells can transdifferentiate into neurons, astrocytes, and microglia in a long-term setting without fusing have revived the transdifferentiation potential. Whether this can apply to marrow stromal cells (MSCs) is presently unclear.

As in the case of OECs and SCs, MSCs remain appealing for autologous transplantation and spinal cord repair because they can be very easily procured, expanded in culture, and delivered via intramedullary or intravenous routes, ${ }^{231}$ among other reasons. ${ }^{232}$ Several studies have been reported on the use of MSCs in midthoracic SCI contusion injury models of varying severity. ${ }^{222,228,233-235}$ All studies show some degree of hindlimb locomotor recovery that in certain cases looks very similar to the level of improvement reported with other experimental cellular therapies in SCI. Disappointingly, the potential mechanisms by which MSCs may be acting are unclear at the existing level of analysis, although neurotrophic ${ }^{233}$ and axonal elongation facilitating $^{228}$ actions have been proposed. Also, the functional outcomes reported must be cautiously interpreted because many are primarily based on one evaluation protocol without other correlative behavioral/electrophysiological approaches.

Clinical translation. At the May, 2004 meeting of the American Society for Neurotransplantation and Repair, a presentation by E. Syková and colleagues on the experimental use of MSCs in $\mathrm{SCI}^{236}$ also included a description of the results of a clinical study that was initiated in September, 2003 at the Motol Hospital in Prague. In that small-scale trial, autologous MSCs were intravenously delivered to nine people (21-41 years old; 7 males; 2 females) who had sustained an SCI either 11-30 days or 2-17.5 months before this procedure. Two patients were injured at $\mathrm{Th}_{9}$; the remaining had injuries at midcervical to low-cervical levels (i.e., $\mathrm{C}_{4}$ to $\mathrm{C}_{7}$ ). Preclinical studies were conducted by this group of investigators, showing the feasibility of this approach and the ability of MSCs to home in on regions of intraspinal cavitation. Autologous, iliac-derived MSCs were harvested and within $5 \mathrm{~h}, \sim 10$ $147 \times 10^{6} \mathrm{CD} 34+$ cells were delivered via the vertebral artery using angiography. No adverse events were noted postoperatively. Findings in 6 of 9 subjects, who are at 3 and 6 months post-MSC delivery, reveal varying degrees of improvement that appear to fall within an expected 
range of spontaneous recovery. Thus, without controls or some indication of cell viability within those lesions at this point, all that may be concluded is that a measure of procedural safety was demonstrated. The most dramatic change was in a $\mathrm{C}_{6}, 41$-year-old male subject who advanced from ASIA B to D with the concomitant reappearance of motor-evoked potentials.

\section{Regenerative repair of the injured spinal cord: activated macrophages}

Preclinical observations. One of the more mature clinical trials in progress is based on studies showing that activated macrophages may be capable of enhancing regeneration in the CNS. Initial laboratory comparisons of inflammatory responses associated with PN injury and regeneration versus $\mathrm{CNS}$ trauma suggested that the lack of regeneration in the spinal cord could be attributed to a compromised recruitment of macrophages. ${ }^{237}$ Subsequent experiments, first in an optic nerve injury model, showed that regeneration could be elicited by augmenting the endogenous inflammatory response with grafts of activated macrophages that had been preincubated in the presence of PN tissue. ${ }^{238,239}$ It was then reported that the same approach in a complete spinal cord transection model led to some recovery of hindlimb function along with the re-emergence of concomitant motor-evoked potentials. $^{240}$ Axonal tracing showed fibers extending through the lesion, and retransection of the spinal cord abolished the previously recovered functions. Details of how the regenerative response evolves, however, have not been reported.

Clinical trials. Clinical application of the original experimental findings using peripherally activated macrophages moved forward under the auspices of Proneuron, Inc. The following summary is based on a public presentation given at the $49^{\text {th }}$ Annual Conference of the American Paraplegia Society. ${ }^{241}$ A phase 1 open-label and nonrandomized trial was initiated in Israel, in collaboration with centers in Brussels (Erasmus Hospital) and Denver (Craig Hospital), which was granted approval by the Food and Drug Association (FDA) in 1999. The first of eight subjects was enrolled in 2000. Candidates for this study were to have confirmed diagnosis of complete $\mathrm{SCI}$ with lesions at $\mathrm{C}_{5}$ to $\mathrm{Th}_{11}$. Treatment, to be done within 2 weeks after injury, involved obtaining a subject's blood and a specimen of full-thickness skin, which was used instead of PN to stimulate macrophage activation. ${ }^{242}$ A comprehensive battery of follow-up neurological and spinal imaging evaluations was proposed.

In the update noted above, it was reported that eight subjects have been enrolled ( 7 males, 1 female) who were between 19 and 41 years of age. All but one had sustained thoracic SCI, and all were ASIA A at the time of enrollment. Treatment was administered between 9 and 14 days after injury. Thus far, no adverse effects have been identified. Three subjects improved to ASIA $\mathrm{C}$, and the time over which this occurred was believed to be well above the expected rate of natural recovery. ${ }^{241}$ Phase 2 trials are presumably now underway that involve study sites in Tel Aviv, Denver, and New York.

\section{Commentary}

One of the issues that has been echoed at two recent conferences on translational SCI research (http://www. ninds.nih.gov/news_and_events/sci_translation_workshop. $\mathrm{htm}$; http://www.icord.org/workshops/iccp.html) and in related venues ${ }^{32}$ is that of independent verification of promising strategies ${ }^{23}$ before the initiation of a clinical trial. Thus, on purely objective grounds, the timeliness of the initial phase 1 study just described could be challenged; however, it becomes even more debatable whether the proposed phase 2 trial is appropriate given that controversy now exists regarding the use of activated macrophages to bolster postinjury inflammatory responses as a way to stimulate regeneration in the injured spinal cord. On one hand, activation of intrinsic macrophages at a spinal contusion site with microinjections of zymosan has been shown to have deleterious effects on hindlimb functional recovery and tissue survival. ${ }^{243}$ Alternatively, the depletion of peripheral macrophages, during a time when inflammation has been shown to be maximal after spinal contusion injury in rats, has been observed to lead to significantly better hindlimb usage during overground locomotion, more extensive white matter sparing, and decreased tissue cavitation. ${ }^{244}$ It should also be noted that the move to the clinic was based on a transection, rather than a contusion, injury model. The results obtained with a contusion model have only been recently published. ${ }^{242}$ In that investigation, skin-incubated (as in the clinical trial), instead of $\mathrm{PN}$-activated macrophages were being used. Because there is significant reason to believe that a well controlled inflammatory response to SCI can be beneficial to axonal regrowth and the phase 1 trial has thus far indicated safety, an argument can certainly be made in favor of more preclinical verification and analysis (including other species) to better appreciate the robustness of the therapy.

\section{CELL-MEDIATED REMYELINATION OF THE INJURED SPINAL CORD}

Considerable experimental evidence has demonstrated that 4-aminopyridine (4-AP), a voltage-sensitive potassium channel blocker, ${ }^{245-247}$ is capable of restoring axonal conduction in demyelinated axons. ${ }^{248}$ Those findings, coupled with primary demyelination and oligodendroglial apoptosis being a consistent feature of post-SCI histopathology and pathophysiology, have generated considerable attention to the use of cellular repair strategies directed at remyelination. ${ }^{25,249}$ In fact, cellular therapeutics for restoring myelin and axonal conduction are currently considered by many to 
have the most immediate potential for restoring some degree of useful function after $\mathrm{SCI},{ }^{36}$ as suggested also by studies of other CNS demyelinative disorders. ${ }^{250}$

\section{Preclinical observations}

Candidate sources of myelin-producing cells, based on both CNS demyelination or injury models, include the following: unmodified and modified $\mathrm{SCs}^{251,252}$ OECs, ${ }^{179,253,254}$ MSCs, ${ }^{255}$ fetal or adult oligodendroglial progenitors to serve as either allogeneic or xenogeneic donor material, ${ }^{256-260}$ and embryonic stem (ES) ${ }^{261-265}$ or adult stem cells. ${ }^{266-268}$ One of the more useful translational features of such myelin-forming cells is they can be used in xenografting models in a clinically and mechanistically predictive way, because myelinogenic competence is retained across species. However, the migratory capacity of human oligodendroglial precursors in a rodent SCI model ${ }^{36,265}$ may be quite different from that in human recipients. Methods to track such donor cells in clinical applications will thus be important here as in other transplantation strategies. ${ }^{269}$ Fundamental issues related to the survival and functions of these cells have also been addressed, and one study ${ }^{270}$ has shown that peak phases of microglial reactivity can contribute to the death of donor oligodendroglial progenitors.

A recent publication ${ }^{271}$ involving grafts of myelinogenically competent donor cells to the demyelinated spinal cord of the subhuman primate provides an important basis for future translational experiences, although some limitations need to be resolved. Highly purified and well characterized OECs were isolated from transgenic pigs. These cells, which expressed the $\alpha(1,2)$ fucosyltransferase (H-transferase or HT) gene, were then transplanted into demyelinated lesions made in the spinal cords of immunosuppressed African green monkeys. HT is significant in its ability to reduce human antibody reactivity and complement-mediated cell lysis. Robust remyelination, resembling peripheral myelin sheaths, was observed 1 month later, with minimal remyelination being present in nontransplanted controls. Those initial findings extend and closely resemble results obtained with engineered porcine cells in rodent demyelinative models. Remyelination, however, was incomplete, and it is unknown how this will relate to therapeutic efficacy in SCI if primary demyelination occurs at great distances from the lesion epicenter, as described in rodents (Liu et al. ${ }^{59}$ ).

\section{Clinical trials}

Publications reporting functional recovery in a rat spinal contusion injury model after transplantation of murine ES cells, which gave rise to oligodendrocytes in vivo and in vitro, ${ }^{263,265}$ were subsequently followed by an announcement in April, 2001 of the initiation of a clinical SCI study conducted by Diacrin, Inc. (now under the name of GenVec, Inc.) in collaboration with investiga- tors at Washington University (St. Louis, MO) and the Albany Medical Center (Albany, NY). According to website accounts, porcine fetal stem cells were grafted into reportedly six subjects who were 1 year or more beyond injury. Immunological "masking" of the pig cells was used to minimize rejection and the need for longterm immunosuppression. The last patient visit for this study was reported to be scheduled for June, 2004, and a manuscript describing the findings will then be prepared for publication (J.W. McDonald, personal communication). Thus far, the procedure appears to be safe. Other trials in restorative SCI involving the transplantation of cells capable of making myelin are being discussed within the academic and biotechnology sectors. It is anticipated that at least two new trials will be initiated. As noted later, whether more scientific due diligence is warranted should perhaps be openly discussed.

\section{NEURONAL REPLACEMENT IN SCI: INTRASPINAL TRANSPLANTATION OF FETAL CNS TISSUE}

Considerable interest is now being directed at the future use of neural stem cells for treating a variety of CNS disorders. Fetal CNS tissue grafting, however, continues to represent an important experimental tool for addressing the challenging task of neuronal replacement, as well as an important benchmark for other evolving donor cell types. In that regard, as discussed elsewhere in this issue of NeuroRx ${ }^{\circledR}$, clinical experiences with fetal grafts in PD have established a vital base of experience and a valuable template for the next generation of clinical trials using cell-based strategies. ${ }^{272}$ Although extension of this approach to clinical SCI has been far more limited, some worthwhile insights have evolved from three, now completed and closed, independent trials that focused on the safety and feasibility of intraspinal transplantation of human fetal spinal cord (huFSC) in a small cohort of SCI subjects in Gainesville, FL, ${ }^{123,273}$, Sweden, Denver, $\mathrm{CO},{ }^{274,275}$ and Russia. ${ }^{276}$

On behalf of the Gainesville experience, the impetus for advancing to the clinical setting first took into account over 15 years of experience and independent research confirmations worldwide related to fetal tissue grafting in SCI models. In addition, the precedent and experience of clinical trials in PD patients added a significant measure of confidence and experience relative to donor tissue safety on which a SCI trial could build. Second, to ensure scientific credibility, the intent to initiate a clinical experience was brought to the attention of the SCI research community at-large in advance of the first transplantation procedure being done. Third, a workshop was held 3 years in advance of the Gainesville study to discuss practically and philosophically when and how to best proceed with bench-to-beside translations. ${ }^{108}$ Many issues raised at that gathering were similar to ones 
now being addressed. ${ }^{23}$ Lastly, translation to human subjects was very closely modeled according to preclinical experiences derived from studies of clinically relevant SCI models in different species. In retrospect, the three trials were not only founded on replicated findings and experience, but they also independently corroborated each other in terms of procedural safety and feasibility. An important consideration is that neural stem/progenitor cells are clearly involved in the overall development and differentiation of fetal CNS transplants. ${ }^{29}$ In principle, these experiences with fetal tissue could serve as a valuable frame of reference for future clinical investigations involving other sources of donor tissue for neuronal replacement.

\section{Preclinical foundation}

Studies of intraspinal transplantation of fetal CNS tissue (fetal spinal cord for this discussion) and the theoretical basis for this approach have been reviewed extensively by this author ${ }^{29,277-279}$ and others. ${ }^{280,281}$ Significant research milestones that collectively established the basis for these trials included multidisciplinary evidence that sequentially identified with clinical conditions in which an intraspinal transplantation approach would be most conceivable. Thus, experimental modeling progressed from partial or complete transections to contusion injuries and from acute to chronic lesion settings. Under those conditions, reproducibly successful survival and robust growth/ differentiation of fetal CNS tissue could be obtained. In the case of contusion injuries, extensive filling of areas of cavitation could be achieved with injections of dissociated cell suspensions. Importantly, basic procedural and neurobiological features of these embryonic grafts in rodents could be extended and reproduced in the cat, a species that has been extensively used in spinal cord research for many years. Before initiating the Gainesville trial, studies were conducted that demonstrated the potential of MR imaging to differentiate between areas of cavitation versus regions in which either partial or complete filling of the cavities was achieved with donor tissue. ${ }^{282,283}$ Despite noted limitations in spatial resolution, MR imaging still proved to have sufficient power for monitoring graft status.

In the PD trials, the need for immunosuppression has been the subject of debate. ${ }^{284}$ However, what might apply to that clinical condition may not be true for intraspinal protocols, because there is considerable inflammatory response to injury 285,286 that may even be exhibited in the chronic state. ${ }^{287}$ The susceptibility of intraspinal fetal CNS grafts to immunological rejection has been observed both in certain rat strains ${ }^{288}$ and cats. ${ }^{289}$ Thus, long-term immunosuppression has been required under various conditions. Interestingly, however, termination of immunosuppression did not always result in graft rejection, suggesting the possibility that temporary immunosuppression, as in some of the PD human tri- als, ${ }^{290,291}$ would be a viable option. More recently, it has been shown that the expression of major histocompatibility complex antigens in first trimester fetal huFSC tissue is not sufficient enough to promote an immune response. ${ }^{284}$ Given, however, that a delayed rejection could still occur, it was important to recognize that under all experimental conditions in which a robust rejection eventually evolved, there was no evidence of adjacent host pathology and/or deterioration of neurological function below the preoperative baseline data. Even under the circumstances of a xenograft rejection, no adverse neurological changes were observed. It thus seemed from a patient safety perspective that a worst-case scenario of a major immunological event might still not present later complications.

Potential patient benefit is obviously a major prerequisite for exploring clinical extrapolation of experimental findings. Although intraspinal fetal CNS grafts had been shown to promote some changes in locomotor performance in both neonatal and adult rats ${ }^{292-296}$ and cats, ${ }^{297-299}$ the level of available functional data was still not substantial enough to fully justify testing these grafts by themselves in human subjects. This was not being overly conservative, because more recent findings indicate that to obtain substantial functional outcomes under certain lesion conditions could require a combination of therapeutic approaches $^{300,301}$ that in many instances may still not be easily applied based on regulatory requirements alone. Nevertheless, it was interesting that fetal spinal cord transplants into sites of midthoracic contusion injuries in rats mitigated lumbar motoneuron hyperexcitability seen after these injuries. This observation was not only important from a transplantation perspective, but also because it led to renewed interest in the neurophysiological principle of "rate modulation" of primary afferent transmission to motoneurons, which has been associated with spasticity in rats ${ }^{302-305}$ and humans after SCI. ${ }^{306,307}$ This finding provided an opportunity for neurophysiological protocols used in animal experiments to be translated to human studies as discussed in more detail below.

In summary, the technology of intraspinal transplantation was well established in two species in which clinically relevant contusion/compression injuries were produced. Some of the cellular dynamics of human fetal tissue in spinal cord lesions had also been documented, ${ }^{308-311}$ showing an absence of overgrowth potential in particular. In other experiments, imaging possibilities were demonstrated that could allow serial, noninvasive evaluation of transplant survival and growth in a contusion injury, and data were available suggesting that temporary immunosuppression could be sufficient to ensure long-term graft viability. Although there were many suggestions of graft-mediated functional improvements, the results at the time, as even now, had to be viewed conservatively. However, no behavioral or other data sug- 
gested that intraspinal transplants of fetal CNS tissue would lead to a deterioration of spared function even in the face of a robust immunological rejection. Lastly, a neurophysiological protocol had been established that could be translated to humans as an objective measure of spasticity that had substantial mechanistic underpinnings.

\section{The clinical experience}

Each of the three clinical trials noted above focused on a subset of SCI patients who were experiencing PTS, which was described earlier in this review. In brief, the underlying rationale was based on the fact that such individuals would be ideally suited for a limited safetyfeasibility study, because a clear medical need existed for spinal surgery as a result of incipient neurological deterioration. Thus, an opportunity existed for superimposing an established preclinical technology onto the standard of medical care. As far as potential patient benefit, the studies by Blagodatskii et al. ${ }^{276}$ and Falci et al. ${ }^{274}$ were initiated with the intent of finding a more effective way to obliterate cysts in these patients and thus curtail the advancing pathology and associated neurological problems. Five patients received huFSC tissue in the Russian study in which no complications were observed, and cyst obliteration was believed to be effective based on delayed-contrast computed tomography and ultrasound. Only one procedure was reported in the study by Falci et al., and a 7-month follow-up with MR imaging suggested that the donor tissue had obliterated a 6-cm segment of the cyst that had been filled with solid FSC tissue.

The first intraspinal fetal tissue transplantation procedure in the U.S. was performed in Gainesville, FL on July 11, 1997, and the initial goal of that endeavor was to determine how safely and effectively approaches being used in the laboratory setting could be translated to the clinical arena. Detailed descriptions of the surgical procedures, preliminary listing of subject profiles, and findings obtained from the first two graft recipients after an 18-month follow-up interval were presented previous$1 y^{29,123,273}$; an additional update of results is in preparation. The design of this trial was to enroll a total of 10 subjects. However, a memorandum circulated by the FDA on November 30, 2000, served notice that as of that date, Investigational New Drug applications were required for the use of fetal cells and tissues in human subjects. Listed examples in that memorandum included "human fetal neuronal cells to treat Parkinson's disease; fetal retinal tissue to prevent blindness; and fetal spinal cord to treat syringomyelia." Recruitment of subjects was stopped for that and other reasons because eight people had already received transplants, and it appeared that sufficient information could be obtained from that cohort. In one case, a participant in this study elected to undergo two separate transplantation procedures. ${ }^{123}$
HuFSC tissue was obtained at 6-9 weeks after conception by elective termination and in accordance with all existing federal, state, and ethical guidelines. With few exceptions in which a myelotomy was performed, pooled donor tissue was delivered into closed cystic compartments as minced pieces in $100 \mu \mathrm{l}$ volumes through a cannula attached to a 500- $\mu$ l syringe. Postoperative neurological outcomes were carefully followed at regular intervals using a comprehensive battery of functional measures (e.g., ASIA, MR, and electrophysiological protocols). Because detethering and cyst drainage were performed as part of the procedure, any noted improvements at this stage of analysis in this open-label, unblinded trial were operationally considered to be more reflective of safety rather than any index of efficacy. Such standard approaches have been reported to lead to some functional improvements. ${ }^{312}$ In contrast with the Sweden/Denver trial, in which immunosuppression was delayed until a month after grafting (see also Akesson et al. ${ }^{284}$ ), the Gainesville study involved immunosuppression beginning 3-4 days before the transplantation procedure and then maintained for 6 months at reduced doses unless earlier cessation was required.

Although several subjects presented unique post-transplantation neurological features, the overall finding was that none experienced short-term or long-term adverse events that were associated with the transplantation procedure itself. The safety implied by that collective observation was most dramatically demonstrated in one individual (here designated as SCI \#5), whose enlarging cyst at the time of transplant surgery was $\sim 1 \mathrm{~cm}$ long (i.e., of similar magnitude to stable lesions in our cat experiments referred to earlier). Pretransplant surgery MR showed substantial spinal tissue was still present, despite progressively declining neurological status. Although it was decided to move forward with the transplantation procedure, a grave concern was the problem of distinguishing between continued neurological declines as a result of the ongoing pathobiology versus a potential negative effect of the graft. Solid pieces of huFSC tissue from two donor fetuses were introduced into that cavity, and MR at 3-24 months postoperatively has shown nearly complete filling of the original cyst, which seemed to be reduced in size (shown in Reier et al. ${ }^{29}$ ). Quite impressively, this person exhibited a remarkably progressive rebound from preoperative compromised gait and proprioception (FIG. 5). Serendipitously, this person's initial gait performance, which included a pronounced unilateral foot drop, was virtually identical to what we have observed and reported in our studies of spinal contused cats (FIG. 6a,b). In accord with the safety-feasibility focus of this trial, the changes seen were conservatively attributed to stabilization of the expanding syrinx and possible accompanying neuroplastic 


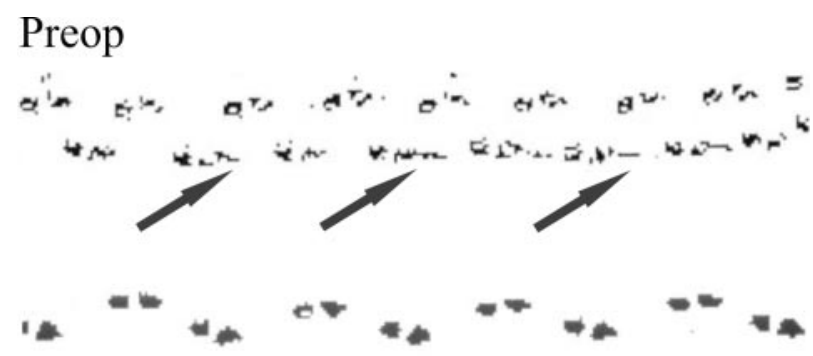

\section{Mos. Postop}

FIG. 5. Gait records obtained from one subject enrolled in the Gainesville human fetal spinal cord trial described in the accompanying text. Overground locomotion was recorded at normal pace $(0.14 \mathrm{~m} / \mathrm{sec})$ and fast pace $(0.19 \mathrm{~m} / \mathrm{sec})$ before surgery and then 3 months post-transplantation (normal pace, $0.55 \mathrm{~m} / \mathrm{sec}$; fast pace, $0.75 \mathrm{~m} / \mathrm{sec}$ ). In addition to achieving faster locomotion after surgery, this individual also showed improved performance relative to a preoperative foot-drop (arrows) which were noticeably absent after transplantation (data obtained by Dr. Andrea Behrman). Preop, preoperative; Postop, postoperative.

events that could have been associated with cyst drainage as well.

The first two individuals enrolled in this study also provided an excellent illustration of safety. ${ }^{123}$ Preoperative neurophysiological assessments showed the presence of upper extremity cortical-evoked potentials indicating the presence of intact pathways that could be at risk if transplantation were to have adverse effects or if the cysts were to continue expanding. The first individual (SCI \#1) showed intramedullary cavitation on MR exam

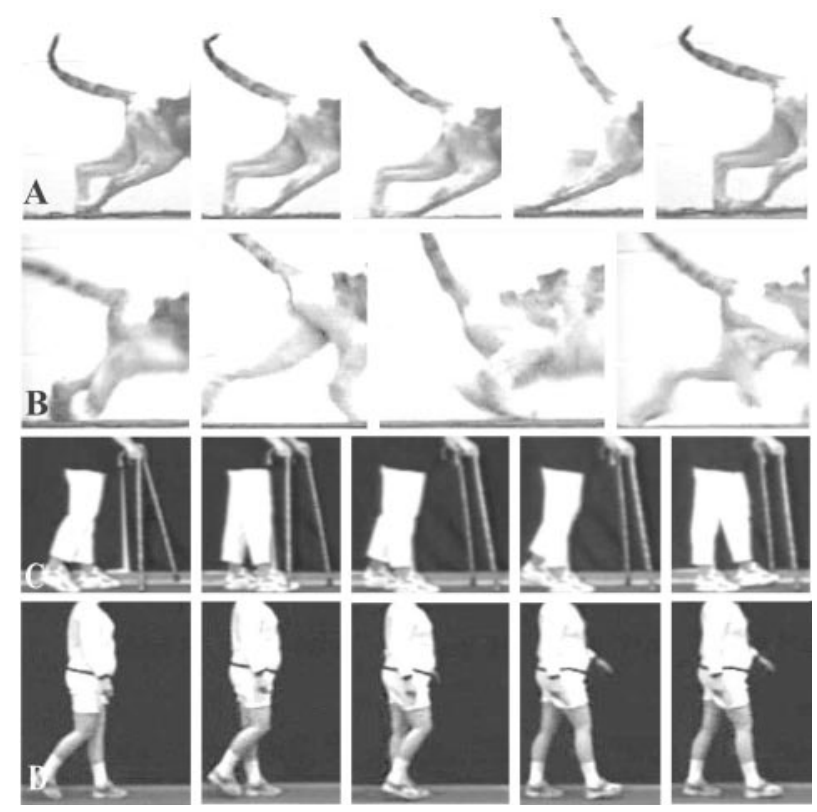

FIG. 6. Translational correspondence between preclinical locomotor performance in a cat before (row A) and after (row B) intraspinal fetal transplant surgery compared with a human subject before (row C) and after (row D) human fetal cell grafting. Before transplantation, both the cat and human subject show a pronounced foot drop (see FIG. 5 for the person in rows $C$ and D) with improved locomotor performance after surgery. extending from Th2 $-\mathrm{L} 1$. The second subject had a fused cyst at the $\mathrm{Th}_{5}-\mathrm{Th}_{6}$ interspace with the rostral component of that cyst extending to $\mathrm{C} 6$ and the caudal portion descending to Th8. No negative effect was identified on this and other neurophysiological measures over the 18 months after transplant surgery. ${ }^{273}$ Participant SCI \#1 was of particular interest because part of the transplant that individual received was in partitioned cavities associated with the lumbar spinal enlargement. As in previous experiments with rats that had received intraspinal FSC allografts, ${ }^{303}$ this person showed an improved stimulus-rate dependence of the H-reflex from the right leg, which suggested partial normalization of the excitability in the corresponding motor neurons (i.e., modulation of spasticity). That cyst drainage alone could have contributed to the attenuation of spasticity ${ }^{312}$ cannot be dismissed.

\section{Commentary}

Relative to preclinical modeling, it should be recognized that PTS represents both a combined chronic and acute injury for which no experimental SCI correlate is known. The focus of these studies on human subjects was thus directed at the more stable, established cystic regions of the spinal cord that approximated the type of pathology addressed by fetal cell transplantation in contusion injury paradigms. Whether the more acute component of PTS could have any bearing on the anatomical or functional outcomes of transplantation is unknown. Nevertheless, taking these findings at face value, three investigative teams have independently obtained similar lines of evidence suggesting the feasibility and safety of intraspinal huFSC transplants in PTS, although this condition only served as a model on which those initial clinical studies could be based.

This raises the issue, however, of procedural versus biological safety, because definitive graft survival was not demonstrated, ${ }^{123}$ although human-to-rat xenografts of unused donor tissue at the end of each transplant procedure confirmed cell viability (FIG. 7). Imaging approaches used by all three of the groups suggested obliteration of cysts in regions in which huFSC tissue had been placed. Falci et al. ${ }^{274}$ made cogent arguments in discussing their interpretation of such MR findings based on observations very similar to our own. However, our preclinical experience in Gainesville leads to more cautious conclusions. Previously described comparisons of in vivo MR images of FSC grafts in intraspinal cysts of spinally contused cats with correlative postmortem histological sections suggested that it should be feasible to visualize viable graft tissue in human recipients. ${ }^{282,283} \mathrm{In}$ those studies, donor tissue could often be distinguished from the host surround. Disappointingly, despite the high quality of the MR images, the fact that a specific donorhost boundary could not be defined in our human trans- 


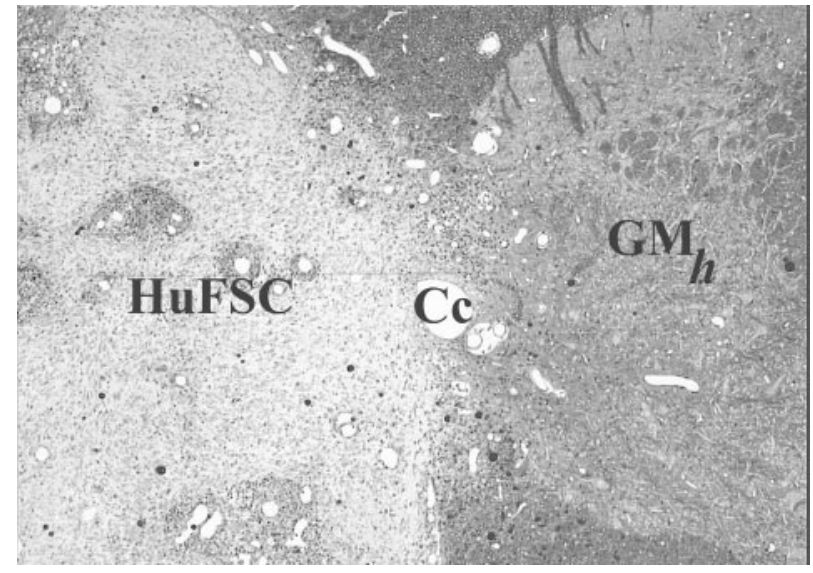

FIG. 7. A transverse section of an adult rat spinal cord in which a transplant was made on one side using human fetal spinal cord (huFSC) tissue remaining after one of the grafting sessions in the Gainesville post-traumatic syringomyelia/fetal cell transplantation trial. Host gray matter $\left(\mathrm{GM}_{\mathrm{h}}\right)$ and central canal (Cc) are identified for reference. This section was obtained 1 month after transplantation. Human fetal tissue xenografts mature slowly, and thus the transplant illustrated is primarily comprised of germinal neuroepithelial cells and a few large blood vessels. This approach provided evidence of the viability of donor tissue used on each patient enrolled in the specified trial.

plant recipients (FIG. 8a) makes it difficult to unequivocally confirm graft survival. This could be attributable to inferior spatial resolution, tissue contrast, or restricted transplant growth. Thus, the most compelling indication of intraspinal huFSC graft survival is by default based essentially on the absence of cavitation at sites of donor tissue placement. To some degree, this is supported by laboratory studies of rats and cats in which failed or rejected grafts typically resulted in the refilling of the injury site with CSF. ${ }^{282,288}$ Therefore, in the absence of more definitive evidence, it may be wiser to interpret results to date as reflecting more a case of procedural, rather than biological, safety in so far as long-term graft survival is unknown.

Because the emphasis of the trial in Gainesville was primarily on safety-feasibility, much significance cannot be attached to even the relatively modest improvements observed. Furthermore, the majority of those changes could be attributed to standard operative procedures for PTS. As noted in our description of the first two subjects, ${ }^{123}$ the MR images showed collapse of only small portions of the cysts. Thus, it was anticipated that any clinical or neurophysiological changes would be primarily related to segmental effects of surgery or donor tissue specifically rather than restored conduction in long white matter tracts. Indeed, the grafts in those two individuals did not lead to any recovery in lower extremity (LE) function on ASIA exam or return of LE cortical-evoked potentials.

In PTS, neurological measures can be highly variable not only on repeated measures from an individual subject
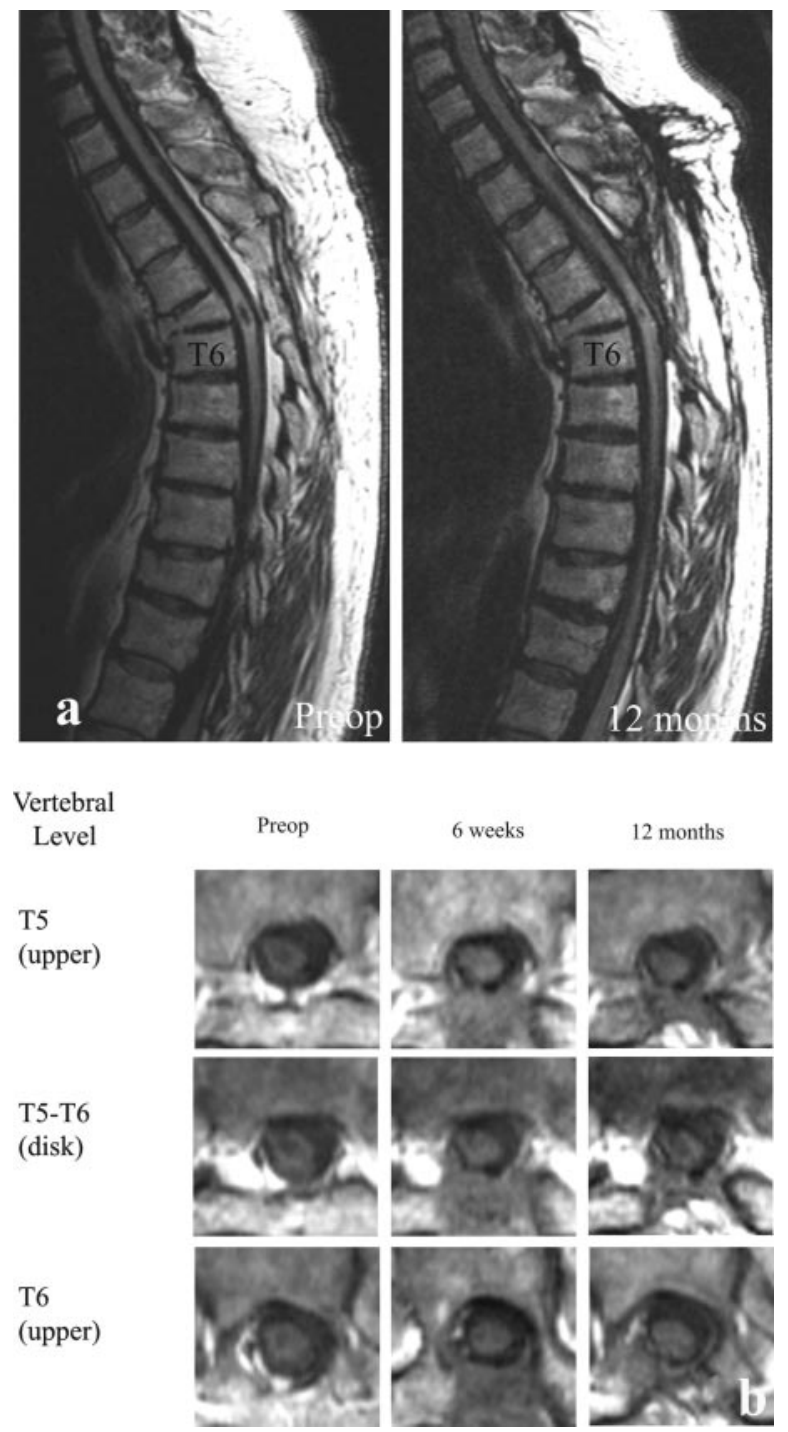

FIG. 8. Sagittal (a) and transverse (b) MR images from the subject whose locomotor function is illustrated in Figures 5 and 6 . This person's injury occurred 30 years before the transplantation procedure. Her presenting neurological symptoms before being enrolled were associated with an expanding syrinx at the $\mathrm{Th}_{5}-\mathrm{Th}_{6}$ interface [preoperative (Preop) image] where a pronounced kyphosis also was evident. One year after surgery, much of the region of cavitation was obliterated, although the host-graft interfaces were not obvious. Comparison with images at 3 months after grafting suggested some cavitation being seen in the region of grafting that was not apparent earlier, although no declining neurological symptoms were detected. Transverse images revealed substantial host tissue preservation before grafting, which represented a substantial risk. Images obtained 6 weeks and 12 months after transplantation suggested significant filling of the cyst; however, changes in graft appearance could be seen between these two times in some sections (e.g., at $\left.\mathrm{Th}_{5}-\mathrm{Th}_{6}\right)$.

but even more between subjects. Using objective neurophysiological criteria, striking differences were observed in rate depression and potentiation in H-reflexes in the first two Gainesville trial participants, ${ }^{273}$ which appeared to correlate with anatomical features of their spinal cords. Data from the second subject varied from one 
recording session to the next. When taking that perspective into account, relative to more subjective functional evaluations, the experience of this clinical study underscored the need for more quantitatively reliable outcome measures for SCI trials, as many investigators are now exploring. Despite outcome variability, it is interesting to note that the PTS studies in Sweden and Gainesville both reported some degree of improvement related to sensation and spasticity. In the former, sensory improvement and pain reduction were maintained over the 7 months reported. Spasticity, however, was initially decreased based on the patient's impressions, but there was a progressive return, although not to preoperative levels.

Although various disclaimers regarding graft survival have been conservatively noted and any inferences about therapeutic efficacy considered premature, the findings of these clinical trials raise some important issues and hypotheses. All three of the studies have noted successful long-term obliteration of cysts that were accompanied by some neurological improvements. Particularly noteworthy is that some individuals enrolled in the Gainesville trial who had previous surgeries for PTS have not shown significant re-expansion of their cysts to a level at which surgical intervention would once more be required. Assuming graft survival, these findings establish a basis for considering whether even incomplete cellular filling of areas of cavitation may not have some enduring benefit in terms of additional progression of PTS and segmental functions at the site(s) of engraftment. From our experience and reports in the literature, it appears that cysts may contribute more to certain aspects of post-SCI dysfunction than has been specifically given credit, and this could imply that reconstruction of cavitated regions may have some benefit to other chronic SCI conditions in addition to PTS. For example, MR showed that the more rostral cyst in our second patient exhibited substantial collapse with a concomitant decrease in pain in the corresponding dermatomes, whereas the delayed expansion of the lower cyst was accompanied by delayed onset of dysesthetic pain in his lower back. Furthermore, the fact that donor tissue was placed into partitioned cysts associated with LE motoneuron pools in SCI \#1 suggests that localized cyst obliteration may have permitted endogenous repair mechanisms (i.e., neuroplasticity), contributing to a mitigation of spasticity. It is tempting to speculate that this occurred by partial reconstruction of gray matter based on more recent lines of experimental evidence, ${ }^{279}$ suggesting a greater degree of FSC segmental functional integration than has been previously recognized. Clearly, unequivocal confirmation of graft viability in a case such as this would add greatly to the testable notion that some form of incremental, donor cell-based repair may be involved in human recipients.

That some form of graft-assisted improvements may be occurring derives to an even greater degree from recent MR and neurological findings in SCI \#5 described above. This person has shown a sustained overall improvement in function that progressively evolved after transplant surgery. On MR examination, her presenting cyst appeared to be extensively filled (FIG. 8a,b). Although additional neurological and MR analysis is required, preliminary information suggests that 5 years after transplantation, this person is now said to be experiencing some deterioration in gait and proprioception, and the last MR series obtained shows a more mottled appearance in the region in which donor tissue had been introduced (FIG. 8a,b). This may reflect a delayed rejection, re-expansion of the cyst, or other mitigating conditions that could be affecting transplant viability. Additional confirmation is required; however, these findings resemble in principle our earlier cat functional data (FIG. 9) in which FSC recipients showed gradual improvements over their own preoperative baseline locomotor scores. In cases in which graft rejection eventually occurred, there was a concomitant precipitous decline approaching pregraft levels.

\section{SUMMARY AND PERSPECTIVES}

Basic research in SCI has made great strides in the last 25 years, and many new insights have generated a more optimistic view of the potential for promoting functional improvements, especially if therapeutic interventions can be coupled with axonal sparing or other endogenous repair mechanisms without interfering with those processes. ${ }^{279}$ The pace at which progress has been made in this field is especially notable in the area of cellular replacement therapies. Neural tissue transplantation, originally viewed as a powerful experimental tool in studies of CNS injury and disease, ${ }^{313}$ has now become a major focus in translational SCI neurobiology.

In several cases, clinical application has already become a reality. In contrast with the fetal cell trials in PD, in which considerable preclinical experience and information had been amassed using multiple models of PD in rats and subhuman primates, ${ }^{33,34,314}$ the rush to the clinic in SCI could be contested in some cases. However, to dwell on whether or not the timing of any specific trial was appropriate, the more pressing issues are: 1) to what degree any trial has been in register with the experimental data supporting its initiation; 2) how much useful information can be garnered from those clinical endeavors, particularly in regard to rigorous outcome measures; and 3) what have those experiences taught in terms of technical, logistical, or biological shortcomings that need additional research and development. From that perspective, it is troubling that given the vast experience with PN grafts into SCI patients, there is virtually no documented evidence of safety or efficacy. On the other hand, the use of olfactory ensheathing glia in hundreds of patients is 

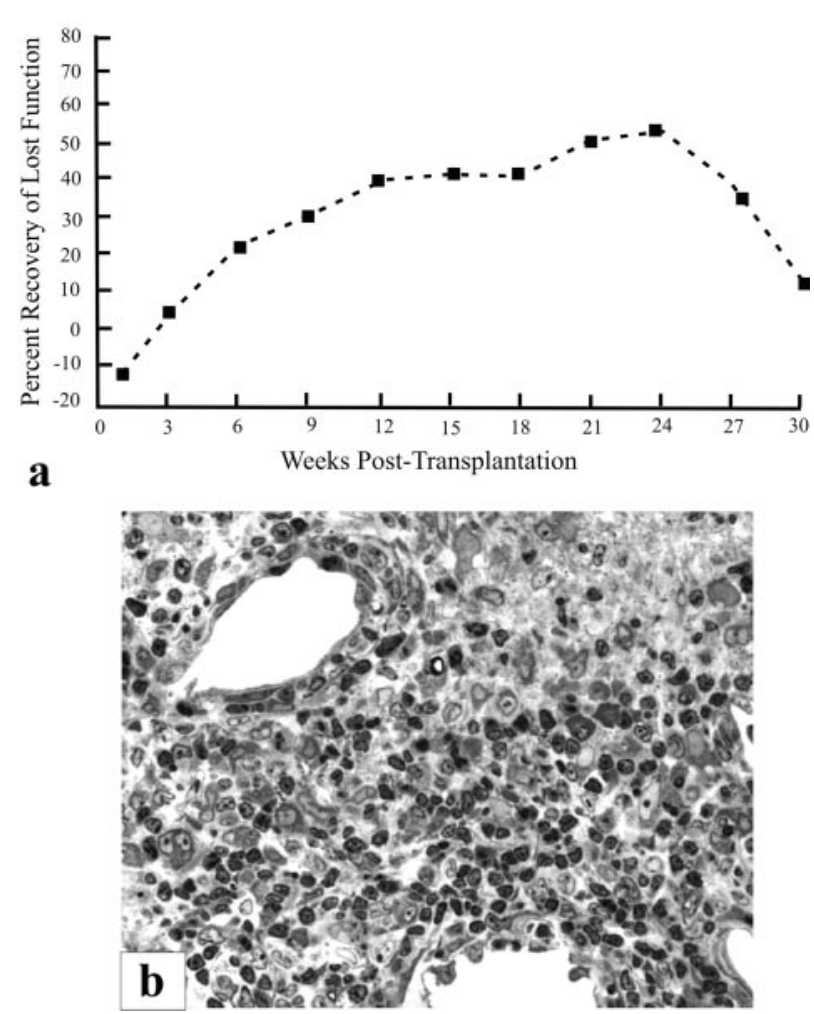

FIG. 9. In a, the post-transplantation functional recovery pattern of adult cats with chronic compression lesions of the spinal cord and grafts of fetal cat spinal cord tissue is shown. Data are based on scoring that established an index of locomotor function. Evaluations were made before and after transplantation, and the postgrafting data are presented as a percentage change relative to pregraft baseline (data extracted from Anderson et al. ${ }^{320}$ ). Five animals received transplants. One animal per postgraft interval was killed at 9, 18, and 24 weeks after grafting. Two animals survived until 30 weeks. One of these cats had a graft undergoing rejection (b) and showed a significant behavioral decline, which contributed to the progressive functional regression shown in this graph between 24 and 30 weeks. Immunological deletion thus suggested some graft-mediated functional recovery, especially because no overt pathology was seen in neighboring host tissue. As noted in the text, a similar pattern is now being seen in one huFSC graft recipient.

also a matter of discussion, because the level of follow-up thus far has been very limited and in light of the very modest study of these cells thus far in laboratory contusion injury models.

One fundamental lesson from the PTS-fetal cell studies is that conventional MR imaging does not permit unequivocal demonstration of graft survival or failure, and given promising results in earlier studies with cats, refinements in MR hardware and/or the development of more advanced imaging protocols seem vital to the interpretation of any clinical data related to true biological safety and efficacy. At present, much of what is being done in humans is essentially dependent on phenomenological and often subjective endpoints. Because optimized therapeutic efficacy will most likely require a combination approach, more effective readouts of graft survival and growth are mandatory. Furthermore, the same imaging issues are likely to apply to other sources of donor tissue (e.g., stem cells) for intraspinal repair. Demonstration of cell survival and migration in human recipients is an area that obviously warrants additional investigation. Another consideration underscored by the PTS trials is the need for more rigorous outcome measures. The ASIA scoring system, for example, although useful in classifying SCI patients, is inadequate for documenting recovery responses that deviate from normal baseline criteria. The need for more objective, quantitative functional measures that could complement existing methods is clearly an issue that keeps surfacing in current discussions about translational SCI research, ${ }^{23}$ and until such measures are in place, the value of any largescale clinical trial in SCI involving a cell-based strategy has to be carefully weighed relative to potential risks and benefits to individual subjects. As in the case of $\mathrm{H}$-reflex measures, used in the PTS trial in Gainesville, much can be learned from translating neurophysiological outcome measures. For example, the principle of rate modulation identified in animals has a well defined mechanistic basis that applies equally to humans. The fact that this objective measure is associated with spasticity argues in favor of its use as a complement to existing, more subjective measures of spasticity that are far less reliable.

Looking ahead to the likely continuing evolution of clinical trials in SCI, there are many as-yet unanswered basic science questions ${ }^{23}$ such as "what constitutes a truly chronic injury"? Longitudinal microarray studies (Velardo et al. ${ }^{315}$ ) may provide important clues. What is/are the window(s) of opportunity for achieving optimal therapeutic benefits? Some indications are available suggesting that interventions used soon after injury may be more effective, ${ }^{316,317}$ yet additional work is necessary.

Other more practical considerations deal with the reproducibility and robustness of a promising strategy. As mentioned, a recurring criticism of the ongoing activated macrophage multicenter trial is that findings made by one investigative group serve as the genesis of those studies. These and related investigations have given impetus for the concept of "protective autoimmunity,"318320 which is directed more at the issue of neuroprotection than regeneration. Although substantial evidence has been accumulated by the same group to support additional clinical trials of an immunization approach, ${ }^{321-323}$ an attempt to replicate those observations has led to contrasting conclusions. ${ }^{324-325}$

Often, the bench-to-bedside extension of an experimental intervention involves a transition from studies in a single rodent strain to testing in a genetically heterogeneous population of individuals. Even if assigned the same ASIA classification, the anatomical and neurophysiological features of lesions conforming to inclusion criteria may differ considerably. Contrasting SCI outcomes are even seen in different rat strains with comparable 
contusion injuries. ${ }^{326,327}$ Therefore, to obtain a more secure readout of the viability of an experimental treatment under clinical conditions, it may be useful to first establish proof-of-principle results under very rigorously controlled conditions in a given rat strain, and then to test the robustness of the approach in a more diverse injury severity and genetic population of rats, as well as across species. A maintained efficacy under such conditions could be more prognostic of what will unfold in a human SCI population.

The ethical and appropriate development of control groups in human trials involving invasive procedures adds another layer of complexity and debate to the evolution of trials involving cell-based strategies. Placebo controls $^{328,329}$ and other experimental designs that can be easily performed in the laboratory are more difficult to employ clinically in a responsible and ethical manner. Likewise, it remains unclear how to control for variability in rehabilitation and other care components that could complicate interpretation of the therapeutic efficacy of a cell-based approach.

Regeneration and/or physiological restoration of longtract systems remains a major focus of many cell-based strategies. These axons in human SCI, however, may not be completely compromised, and for that reason, the repair process is obviously a far more complex and challenging problem. The necessity of gray matter repair cannot be dismissed, especially with regard to lesions at cervical and lumbar levels, but restoring gray matter continuity, even in a thoracic injury, may be important to the overall restoration of appropriate neuronal excitability patterns in the spinal cord at the very least. Although there are now many novel options for donor tissue and neuronal replacement available, much remains to be learned about how to effectively reconstruct a damaged nervous system before the value of any cell source for this purpose can be fully recognized. From that perspective, transplantation of fetal CNS tissue continues to be an effective experimental tool and a gold standard for many evolving cellular technologies. Furthermore, the cellular diversity of fetal CNS grafts, not yet achieved with other cell sources, offers many opportunities for defining which neuronal populations are critical to the recovery of certain functions via segmental circuit reconstruction. In that regard, short of motoneuron replacement, the use of neuronal precursors for SCI in clinical trials now resembles more like what bricks and mortar would be to a builder who has no blueprint. The fact that even neuronally restricted precursors fail to retain their neuronal fates in the injured spinal cord ${ }^{330,331}$ represents another major hurdle to overcome before a rationale for clinical application of stem cells in SCI can be fully justified for neuronal replacement. In light of most recent observations with huFSC grafts in PTS patients, the question arises whether additional clinical efforts with this donor material should be totally abandoned. ${ }^{272}$ Whether fetal CNS tissue can serve as a control for other donor cells is a possibility warranting additional consideration.

Various lines of experimental evidence suggest that using cells to promote remyelination of spared axons can be the most immediately viable cell-based strategy for SCI. It is unclear, however, whether oligodendrocyte replacement would have equal benefit in all cases of SCI, because observations of human specimens have suggested that primary demyelination may be less common than suggested in animal models. ${ }^{35,39}$ Furthermore, at present, there are no studies in animal models of spinal cord injury showing unequivocal evidence of remyelination-based, significant functional recovery. Questions must also be asked regarding the reproducibility in animals and humans of demyelination, the distributions of demyelinated internodes relative to the site of injury, and the critical window post-SCI in which remyelination must be achieved. Whether more advanced MR, such as diffusion-weighted and other newer-generation imaging approaches, can be used to effectively monitor demyelination/remyelination in the injured spinal cord needs additional exploration.

In conclusion, it is imperative to realize that initial translational experiences primarily represent, at least in principle, an advance to another species-in this case humans-and not an immediate prelude to a cure. The license for doing so requires significant proofs-of-principle from animal models and evidence of potential patient benefit. Whether mechanisms underlying recoveries in animal studies need to be fully appreciated is an unsettled issue, although a robust therapeutic effect alone would be sufficient impetus to move forward. An absence of any sense of mechanism, however, would be a major disadvantage whenever a trial failed to fulfill the preclinical findings and expectations; knowing where to look for differences may be difficult without some theoretical guidance. By reaching another point on the learning curve, the very least that should be expected from a clinical study is information that can help define more targeted laboratory investigations based on specific aspects of a human condition. As the fetal cell transplantation experience in PD has demonstrated, ${ }^{272}$ such instructive information, including measures of safety, can then be used to shape an even better conceived secondgeneration translational study that would hopefully move closer to the cure. At the same time, both basic science and clinical efforts should proceed in parallel as much as possible.

From this overall perspective, the experience with huFSC grafts in PTS has provided an unexpected template that was, in retrospect, in fundamental compliance, if not more so, with guidelines that were more recently articulated for a range of neurological disorders ${ }^{32}$ and 
which are now being further expanded in specific reference to future clinical studies in SCI (Tuszynski et al., in preparation). The PTS trials have taught a great deal about the use of cellular transplants and clinical design and implementation issues from only a very small group of subjects. This was possible only because of the close interaction and mutual respect basic researchers and clinicians had for each other and their commitment to the endeavor. Another contribution to the success of those trials, especially the two in Gainesville and Sweden, was the incorporation of preclinical experiences into the design of the respective studies. From a basic scientist's perspective, however, the value of the PTS trial in Gainesville, at least, was not just the emphasis on fetal tissue per se, but more on the opportunity to gain a greater first-hand appreciation for human SCI and what issues still have to be addressed at the laboratory level.

Cell-based therapies thus have demonstrated great potential for SCI, and clearly there is now a greater sense of urgency and pressure being put on researchers to move as expeditiously to the clinic as possible. Although this overview has underscored the extreme need for caution and solid preclinical foundations, the message is not one to discourage advances to human subjects but rather to emphasize that trials should be designed to ensure that as much can be gained from studies of human subjects as possible. This may seem simplistic, however, as this review demonstrates, many trials with cells have already taken place in which limited outcome measures have been sought or in which follow-ups were very modest. Despite all of the reservations and caveats, it is encouraging that procedural safety has been identified in many diverse experiences thus far; however, unequivocal demonstration of biological safety remains an issue.

Acknowledgments: I thank Dr. Naomi Kleitman for taking the time to read this manuscript in its final stages of preparation and for her extremely helpful editorial suggestions. I also express gratitude to Drs. John McDonald and Eva Syková for their willingness to share information related to their respective clinical endeavors.

Some considerations raised in this review were inspired by two recent workshops on translational SCI research that were held in Bethesda, Maryland (http://www.ninds.nih.gov/news and_events/sci_translation_workshop.htm) and Vancouver, British Columbia, Canada (http://www.icord.org/workshops/iccp. $\mathrm{html}$ ). However, all opinions expressed in this review are solely those of the author and thus are not intended to reflect specific discussions at those meetings or the expressed views of the organizers and participants.

Special recognition is also extended to my colleagues, Drs. Edward Wirth III and Douglas Anderson, along with many others, who made the Gainesville clinical trial reviewed here possible. That trial, except for patient services partly defrayed by a National Institutes of Health (NIH) Clinical Research Center Award, was funded through nonfederal resources. Other original research of this author and his colleagues referred to in this review was supported primarily through NIH Program
Project and Investigator-initiated funding, the Mark F. and C.M. and K.E. Overstreet Funds for Spinal Cord Injury and Regeneration Research, the State of Florida Brain and Spinal Cord Injury Research Trust Fund, the Veterans Administration Merit Review, and Paralyzed Veterans of America.

\section{REFERENCES}

1. Kao CC, Bunge RP, Reier PJ. Spinal cord reconstruction. New York: Raven Press, 1983.

2. Sugar O, Gerard RW. Spinal cord regeneration in the rat. J Neurophysiol 3:1-19, 1940 .

3. Hulsebosch CE. Recent advances in pathophysiology and treatment of spinal cord injury. Adv Physiol Educ 26:238-255, 2002.

4. DeFelipe J, Jones EG. Cajal's degeneration and regeneration of the nervous system (May RM, translator). New York: Oxford University Press, 1991.

5. David S, Aguayo AJ. Axonal elongation into peripheral nervous system "bridges" after central nervous system injury in adult rats. Science 214:931-933, 1981.

6. Nornes H, Björklund A, Stenevi U. Reinnervation of the denervated adult spinal cord of rats by intraspinal transplants of embryonic brainstem neurons. Cell Tissue Res 230:15-35, 1983.

7. Björklund A, Stenevi U, Dunnett SB. Transplantation of brainstem monoaminergic "command" systems: models for functional reactivation of damaged CNS circuitries. In: Spinal cord reconstruction (Kao CC, Bunge RP, Reier PJ, eds), pp 397-413. New York: Raven Press, 1983.

8. Bareyre FM, Schwab ME. Inflammation, degeneration and regeneration in the injured spinal cord insights from DNA microarrays. Trends Neurosci 26:555-563, 2003.

9. Muir GD, Webb AA. Mini-review assessment of behavioural recovery following spinal cord injury in rats. Eur $J$ Neurosci 12:3079-3086, 2000 .

10. Kesslak JP, Keirstead HS. Assessment of behavior in animal models of spinal cord injury. J Spinal Cord Med 26:323-328, 2003.

11. Whishaw IQ, Pellis SM, Gorny B, Kolb B, Tetzlaff W. Proximal and distal impairments in rat forelimb use in reaching follow unilateral pyramidal tract lesions. Behav Brain Res 56:59-76, 1993.

12. Schallert T, Fleming SM, Leasure JL, Tillerson JL, Bland ST. CNS plasticity and assessment of forelimb sensorimotor outcome in unilateral rat models of stroke, cortical ablation, parkinsonism and spinal cord injury. Neuropharmacology 39:777-787, 2000.

13. Wrathall JR, Pettegrew RK, Harvey F. Spinal cord contusion in the rat production of graded, reproducible, injury groups. Exp Neurol 88:108-122, 1985.

14. Gruner JA. A monitored contusion model of spinal cord injury in the rat. $J$ Neurotrauma 9:123-128, 1992.

15. Stokes BT. Experimental spinal cord injury a dynamic and verifiable injury device. J Neurotrauma 9:129-134, 1992.

16. Scheff SW, Rabchevsky AG, Fugaccia I, Main JA, Lumpp JE Jr. Experimental modeling of spinal cord injury characterization of a force-defined injury device. J Neurotrauma 20:179-193, 2003.

17. Stokes BT, Jakeman LB. Experimental modelling of human spinal cord injury a model that crosses the species barrier and mimics the spectrum of human cytopathology. Spinal Cord 40: 101-109, 2002.

18. Young W. Spinal cord contusion models. In: Spinal cord trauma: regeneration, neural repair, and functional recovery (McKerracher L, Doucet G, Rossignol S, eds), pp 231-255. Amsterdam: Elsevier, 2002.

19. Wrathall JR. Weight-drop models of experimental spinal cord injury. In: Neurotrauma (Narayan RJ, Wilberger JE, Povlishock JT, eds), pp 1381-1394. New York: McGraw-Hill, 1995.

20. Bregman BS. Regeneration in the spinal cord. Curr Opin Neurobiol 8:800-807, 1998.

21. Murray M. Therapies to promote CNS repair. In: Regeneration in the central nervous system (Murray M, Ingoglia NA, eds), pp 649-673. New York: Marcel Dekker, 2001.

22. Bregman BS, Coumans J-V, Dai HN et al. Transplants and neurotrophic factors increase regeneration and recovery of function 
after spinal cord injury. In: Spinal cord trauma: neural repair and functional recovery. Progress in brain research (McKerracher L, Doucet G, Rossignol S, eds), Vol 137, pp 257-273. Amsterdam: Elsevier Science, 2002.

23. Kleitman N. Keeping promises: translating basic research into new spinal cord injury therapies. J Spinal Cord Med 27:311-318, 2004.

24. Jones DG, Anderson ER, Galvin KA. Spinal cord regeneration moving tentatively towards new perspectives. NeuroRehabilitation 18:339-351, 2003.

25. McDonald JW, Becker D. Spinal cord injury: promising interventions and realistic goals. Am J Phys Med Rehabil 82:S38-S49, 2003.

26. Becker D, Sadowsky CL, McDonald JW. Restoring function after spinal cord injury. Neurologist 9:1-15, 2003.

27. Schwab ME. Repairing the injured spinal cord. Science 295: 1029-1031, 2002.

28. Tator $\mathrm{CH}$. Strategies for recovery and regeneration after brain and spinal cord injury. Inj Prev 8 [Suppl 4]:IV33-IV36, 2002.

29. Reier PJ, Thompson FJ, Fessler RG, Anderson DK, Wirth ED III. Spinal cord injury and fetal CNS tissue transplantation: an initial "bench-to-bedside" translational research experience. In: Regeneration in the central nervous system (Ingoglia NA, Murray M, eds), pp 603-647. New York: Marcel-Dekker, 2001.

30. Horner PJ, Gage FH. Regenerating the damaged central nervous system. Nature 407:963-970, 2001.

31. McDonald JW. Repairing the damaged spinal cord. Sci Am 281: 64-73, 1999.

32. Redmond DE, Freeman T. The American Society for Neural Transplantation and Repair considerations and guidelines for studies of human subjects. The practice committee of the society. Approved by council. Cell Transplant 10:661-664, 2001.

33. Björklund A, Lindvall O. Cell replacement therapies for central nervous system disorders. Nat Neurosci 3:537-544, 2000.

34. Dunnett SB, Björklund A, Lindvall O. Cell therapy in Parkinson's disease-stop or go? Nat Rev Neurosci 2:365-369, 2001.

35. Norenberg MD, Smith J, Marcillo A. The pathology of human spinal cord injury defining the problems. J Neurotrauma 21:429440, 2004.

36. McDonald JW, Becker D, Holekamp TF et al. Repair of the injured spinal cord and the potential of embryonic stem cell transplantation. J Neurotrauma 21:383-393, 2004.

37. Dumont RJ, Okonkwo DO, Verma S et al. Acute spinal cord injury, part I pathophysiologic mechanisms. Clin Neuropharmacol 24:254-264, 2001.

38. Velardo MJ, Reier PJ, Anderson DK. Acute spinal cord injury. In: Neurosurgery: the scientific basis of clinical practice (Crockard A, Hayward R, Hoff J, eds), pp 499-515. Oxford: Blackwell Science Ltd., 1999.

39. Kakulas BA. A review of the neuropathology of human spinal cord injury with emphasis on special features. J Spinal Cord Med 22:119-224, 1999.

40. Hayes KC, Kakulas BA. Neuropathology of human spinal cord injury sustained in sports-related activities. $J$ Neurotrauma 14: 235-248, 1997.

41. Tator $\mathrm{CH}$. Update on the pathophysiology and pathology of acute spinal cord injury. Brain Pathol 5:407-413, 1995.

42. Young W. Spinal cord injury pathophysiology and therapy. In: Neurotrauma (Narayan RJ, Wilberger JE, Povlishock JT, eds), pp 1075-1093. New York: McGraw-Hill, 1995.

43. Bunge RP. Clinical implications of recent advances in neurotrauma research. In: The neurobiology of central nervous system trauma (Salzman SK, Faden AI, eds), pp 329-339. New York: Oxford University Press, 1994.

44. Bunge RP, Puckett WR, Becerra JL, Marcillo A, Quencer RM. Observations on the pathology of human spinal cord injury. A review and classification of 22 new cases with details from a case of chronic cord compression with extensive focal demyelination. Adv Neurol 59:75-90, 1993.

45. Anderson DK, Hall ED. Pathophysiology of spinal cord trauma. Ann Emerg Med 22:987-992, 1993.

46. Kakulas BA. Pathology of spinal injuries. Cent Nerv Syst Trauma $1: 117-129,1984$
47. Profyris C, Cheema SS, Zang D, Azari MF, Boyle K, Petratos S. Degenerative and regenerative mechanisms governing spinal cord injury. Neurobiol Dis 15:415-436, 2004.

48. Nesic O, Svrakic NM, Xu GY et al. DNA microarray analysis of the contused spinal cord effect of NMDA receptor inhibition. J Neurosci Res 68:406-423, 2002.

49. Carmel JB, Galante A, Soteropoulos P et al. Gene expression profiling of acute spinal cord injury reveals spreading inflammatory signals and neuron loss. Physiol Genomics 7:201-213, 2001.

50. Song G, Cechvala C, Resnick DK, Dempsey RJ, Rao VL. GeneChip analysis after acute spinal cord injury in rat. $J$ Neurochem 79:804-815, 2001

51. Citron BA, Arnold PM, Sebastian C et al. Rapid upregulation of caspase- 3 in rat spinal cord after injury mRNA, protein, and cellular localization correlates with apoptotic cell death. Exp Neurol 166:213-226, 2000.

52. Tachibana T, Noguchi K, Ruda MA. Analysis of gene expression following spinal cord injury in rat using complementary DNA microarray. Neurosci Lett 327:133-137, 2002.

53. Giovanni SD, Knoblach SM, Brandoli C, Aden SA, Hoffman EP, Faden AI. Gene profiling in spinal cord injury shows role of cell cycle in neuronal death. Ann Neurol 53:454-468, 2003.

54. Dong H, Fazzaro A, Xiang C, Korsmeyer SJ, Jacquin MF, McDonald JW. Enhanced oligodendrocyte survival after spinal cord injury in Bax-deficient mice and mice with delayed Wallerian degeneration. J Neurosci 23:8682-8691, 2003.

55. Beattie MS, Farooqui AA, Bresnahan JC. Review of current evidence for apoptosis after spinal cord injury. $J$ Neurotrauma 17:915-925, 2000.

56. Springer JE, Asbill RD, Knapp PE. Activation of the caspase-3 apoptotic cascade in traumatic spinal cord injury. Nat Med 5:943946, 1999.

57. Yong C, Arnold PM, Zoubine MN et al. Apoptosis in cellular compartments of rat spinal cord after severe contusion injury. J Neurotrauma 15:459-472, 1998.

58. Crowe MJ, Bresnahan JC, Shuman SL, Masters JN, Beattie MS Apoptosis and delayed degeneration after spinal cord injury in rats and monkeys. Nat Med [Erratum 3:240, 1997] 3:73-76, 1997.

59. Liu XZ, Xu XM, Hu R et al. Neuronal and glial apoptosis after traumatic spinal cord injury. J Neurosci 17:5395-5406, 1997.

60. Shuman SL, Bresnahan JC, Beattie MS. Apoptosis of microglia and oligodendrocytes after spinal cord contusion in rats. $J \mathrm{Neu}$ rosci Res 50:798-808, 1997.

61. Li GL, Brodin G, Farooque M et al. Apoptosis and expression of Bcl-2 after compression trauma to rat spinal cord. J Neuropathol Exp Neurol 55:280-289, 1996.

62. Bunge RP, Puckett WR, Hiester ED. Observations on the pathology of several types of human spinal cord injury, with emphasis on the astrocyte response to penetrating injuries. Adv Neurol 72:305-315, 1997.

63. Blight AR. Cellular morphology of chronic spinal cord injury in the cat analysis of myelinated axons by line-sampling. Neuroscience 10:521-543, 1983.

64. Kakulas, BA. A review of the neuropathology of human spinal cord injury with emphasis on special features. J Spinal Cord Med 22:119-124, 1999.

65. Raineteau O, Schwab ME. Plasticity of motor systems after incomplete spinal cord injury. Nat Rev Neurosci 2:263-273, 2001.

66. Helgren ME, Goldberger ME. The recovery of postural reflexes and locomotion following low thoracic hemisection in adult cats involves compensation by undamaged primary afferent pathways. Exp Neurol 123:17-34, 1993.

67. Young W. Recovery mechanisms in spinal cord injury: implications for regenerative therapy. In: Neural regeneration and transplantation (Seil FJ, ed), pp 157-169. New York: Liss, 1988.

68. Weijer C, Miller PB. When are research risks reasonable in relation to anticipated benefits? Nat Med 10:570-573, 2004.

69. Basso DM. Neuroanatomical substrates of functional recovery after experimental spinal cord injury implications of basic science research for human spinal cord injury. Phys Ther 80:808-817, 2000. 
70. Casas CE, Guest JD. Percutaneous endoscopic cellular transplantation into the lower lumbar spinal cord. Neurosurgery 54:950955, 2004.

71. Chen A, Xu XM, Kleitman N, Bunge MB. Methylprednisolone administration improves axonal regeneration into Schwann cell grafts in transected adult rat thoracic spinal cord. Exp Neurol 138:261-276, 1996.

72. Björklund A, Stenevi U. Intracerebral neural implants neuronal replacement and reconstruction of damaged circuitries. Annu Rev Neurosci 7:279-308, 1984.

73. Stelzner DJ, Cullen JM. Do propriospinal projections contribute to hindlimb recovery when all long tracts are cut in neonatal or weanling rats? Exp Neurol 114:193-205, 1991.

74. Goldstein B, Hammond MC, Stiens SA, Little JW. Posttraumatic syringomyelia: profound neuronal loss, yet preserved function. Arch Phys Med Rehabil 79:107-112, 1998.

75. Anderson KD. Targeting recovery: Priorities of the spinal cord injured population. J Neurotrauma 2004 (in press).

76. Magnuson DS, Trinder TC, Zhang YP, Burke D, Morassutti DJ, Shields CB. Comparing deficits following excitotoxic and contusion injuries in the thoracic and lumbar spinal cord of the adult rat. Exp Neurol 156:191-204, 1999.

77. Webb AA, Muir GD. Unilateral dorsal column and rubrospinal tract injuries affect overground locomotion in the unrestrained rat. Eur J Neurosci 18:412-422, 2003.

78. Webb AA, Muir GD. Compensatory locomotor adjustments of rats with cervical or thoracic spinal cord hemisections. $J$ Neurotrauma 19:239-256, 2002.

79. Mills CD, Johnson KM, Hulsebosch CE. Role of group II and group III metabotropic glutamate receptors in spinal cord injury. Exp Neurol 173:153-167, 2002.

80. Mills CD, Grady JJ, Hulsebosch CE. Changes in exploratory behavior as a measure of chronic central pain following spinal cord injury. J Neurotrauma 18:1091-1105, 2001.

81. Yezierski RP, Park SH. The mechanosensitivity of spinal sensory neurons following intraspinal injections of quisqualic acid in the rat. Neurosci Lett 157:115-119, 1993.

82. Yezierski RP, Liu S, Ruenes GL, Kajander KJ, Brewer KL. Excitotoxic spinal cord injury behavioral and morphological characteristics of a central pain model. Pain 75:141-155, 1998.

83. Yezierski RP. Pain following spinal cord injury the clinical problem and experimental studies. Pain 68:185-194, 1996.

84. Acosta-Rua AJ, Vierck CJ. Effects of excitatory amino acid (EAA) lesions of thoracic spinal gray matter on escape and withdrawal/licking responses of rats to thermal stimulation. Soc Neurosci Abstr 25:1680, 1999.

85. Hubscher $\mathrm{CH}$, Johnson RD. Changes in neuronal receptive field characteristics in caudal brain stem following chronic spinal cord injury. J Neurotrauma 16:533-541, 1999.

86. Hubscher CH, Johnson RD. Effects of acute and chronic midthoracic spinal cord injury on neural circuits for male sexual function. I. Ascending pathways. J Neurophysiol 82:1381-1389, 1999.

87. McKenna JE, Prusky GT, Whishaw IQ. Cervical motoneuron topography reflects the proximodistal organization of muscles and movements of the rat forelimb a retrograde carbocyanine dye analysis. J Comp Neurol 419:286-296, 2000.

88. Marino RJ, Herbison GJ, Ditunno JF Jr. Peripheral sprouting as a mechanism for recovery in the zone of injury in acute quadriplegia a single-fiber EMG study. Muscle Nerve 17:1466-1468, 1994.

89. Jordan LM, Schmidt BJ. Propriospinal neurons involved in the control of locomotion: potential targets for repair strategies? Prog Brain Res 137:125-139, 2002.

90. Hadi B, Zhang YP, Burke DA, Shields CB, Magnuson DS. Lasting paraplegia caused by loss of lumbar spinal cord interneurons in rats: no direct correlation with motor neuron loss. J Neurosurg 93:266-75, 2000

91. Chung K, Coggeshall RE. Propriospinal fibers in the white matter of the cat sacral spinal cord. J Comp Neurol 269:612-617, 1988.

92. Basso DM, Beattie MS, Bresnahan JC. Descending systems contributing to locomotor recovery after mild or moderate spinal cord injury in rats experimental evidence and a review of literature. Restor Neurol Neurosci 20:189-218, 2002.

93. Goldberger ME. Spared-root deafferentation of a cat's hindlimb hierarchical regulation of pathways mediating recovery of motor behavior. Exp Brain Res 73:329-342, 1988.

94. Goldberger ME. Partial and complete deafferentation of cat hindlimb the contribution of behavioral substitution to recovery of motor function. Exp Brain Res 73:343-353, 1988.

95. Alstermark B, Lundberg A, Pettersson LG, Tantisira B, Walkowska M. Motor recovery after serial spinal cord lesions of defined descending pathways in cats. Neurosci Res 5:68-73, 1987.

96. Tantisira B, Alstermark B, Isa T, Kummel H, Pinter M. Motoneuronal projection pattern of single $\mathrm{C} 3-\mathrm{C} 4$ propriospinal neurones. Can J Physiol Pharmacol 74:518-530, 1996.

97. Bareyre FM, Kerschensteiner M, Raineteau O, Mettenleiter TC, Weinmann O, Schwab ME. The injured spinal cord spontaneously forms a new intraspinal circuit in adult rats. Nat Neurosci 7:269-277, 2004

98. Mellen N, Kiemel T, Cohen AH. Correlational analysis of fictive swimming in the lamprey reveals strong functional intersegmental coupling. J Neurophysiol 73:1020-1030, 1995.

99. McClellan AD, Hagevik A. Coordination of spinal locomotor activity in the lamprey long-distance coupling of spinal oscillators. Exp Brain Res 126:93-108, 1999.

100. Burns AS, Ditunno JF. Establishing prognosis and maximizing functional outcomes after spinal cord injury: a review of current and future directions in rehabilitation management. Spine 26: S137-S145, 2001.

101. Tator CH. Epidemiology and general characteristics of the spinal cord injury patient. In: Contemporary management of spinal cord injury (Benzel EC, Tator $\mathrm{CH}$, eds), pp 9-13. Parkridge, IL: American Association of Neurological Surgeons, 1995.

102. Bolser DC, Reier PJ. Inspiratory and expiratory patterns of the pectoralis major muscle during pulmonary defensive reflexes. J Appl Physiol 85:1786-1792, 1998.

103. Krassioukov AV, Furlan JC, Fehlings MG. Autonomic dysreflexia in acute spinal cord injury an under-recognized clinical entity. J Neurotrauma 20:707-716, 2003.

104. Weaver LC, Marsh DR, Gris D, Meakin SO, Dekaban GA. Central mechanisms for autonomic dysreflexia after spinal cord injury. Prog Brain Res 137:83-95, 2002.

105. Widerstrom-Noga E, Cruz-Almeida Y, Krassioukov A. Is there a relationship between chronic pain and autonomic dysreflexia in persons with cervical spinal cord injury? J Neurotrauma 21:195204, 2004.

106. Burns AS, Lee BS, Ditunno JF Jr, Tessler A. Patient selection for clinical trials the reliability of the early spinal cord injury examination. J Neurotrauma 20:477-482, 2003.

107. Fawcett JW. Spinal cord repair from experimental models to human application. Spinal Cord 36:811-817, 1998.

108. Reier PJ, Anderson DK, Young W, Michel ME, Fessler R. Workshop on intraspinal transplantation and clinical application. J Neurotrauma 11:369-377, 1994.

109. Goldberger ME, Murray M. Patterns of sprouting and implications for recovery of function. In: Functional recovery in neurological disease. Advances in neurology (Waxman SG, ed), Vol 47, pp 361-386. New York: Raven Press, 1988.

110. Guth L, Barrett CP, Donati EJ, Anderson FD, Smith MV, Lifson M. Essentiality of a specific cellular terrain for growth of axons into a spinal cord lesion. Exp Neurol 88:1-12, 1985.

111. Beattie MS, Bresnahan JC, Komon J et al. Endogenous repair after spinal cord contusion injuries in the rat. Exp Neurol 148: 453-463, 1997.

112. Weidner N, Tuszynski MH. Spontaneous plasticity in the injured spinal cord-implications for repair strategies. Mol Psychiatry 7:9-11, 2002.

113. Brook GA, Plate D, Franzen R et al. Spontaneous longitudinally orientated axonal regeneration is associated with the Schwann cell framework within the lesion site following spinal cord compression injury of the rat. J Neurosci Res 53:51-65, 1998.

114. Corbetta M, Burton H, Sinclair RJ, Conturo TE, Akbudak E, McDonald JW. Functional reorganization and stability of somato- 
sensory-motor cortical topography in a tetraplegic subject with late recovery. Proc Natl Acad Sci USA 99:17066-17071, 2002.

115. Goshgarian HG. The crossed phrenic phenomenon a model for plasticity in the respiratory pathways following spinal cord injury. J Appl Physiol 94:795-810, 2003.

116. Nantwi KD, El-Bohy A, Schrimscher GW, Reier PJ, Goshgarian HG. Spontaneous functional recovery in a paralyzed hemidiaphragm following upper cervical spinal cord injury in adult rats. Neurorehab Neural Repair 13:225-234, 2000.

117. Golder FJ, Reier PJ, Bolser DC. Altered respiratory motor drive after spinal cord injury supraspinal and bilateral effects of a unilateral lesion. J Neurosci 21:8680-8689, 2001.

118. Golder FJ, Fuller DD, Davenport PW, Johnson RD, Reier PJ, Bolser DC. Respiratory motor recovery after unilateral spinal cord injury eliminating crossed phrenic activity decreases tidal volume and increases contralateral respiratory motor output. J Neurosci 23:2494-2501, 2003.

119. Beattie MS, Leedy MG, Bresnahan JC. Evidence for alterations of synaptic inputs to sacral spinal reflex circuits after spinal cord transection in the cat. Exp Neurol 123:35-50, 1993.

120. Weidner N, Ner A, Salimi N, Tuszynski MH. Spontaneous corticospinal axonal plasticity and functional recovery after adult central nervous system injury. Proc Natl Acad Sci USA 98:3513$3518,2001$.

121. Kim ES, Kim GM, Lu X, Hsu CY, Xu XM. Neural circuitry of the adult rat central nervous system after spinal cord injury a study using fast blue and the Bartha strain of pseudorabies virus. $J$ Neurotrauma 19:787-800, 2002.

122. Hill CE, Beattie MS, Bresnahan JC. Degeneration and sprouting of identified descending supraspinal axons after contusive spinal cord injury in the rat. Exp Neurol 171:153-169, 2001.

123. Wirth ED, III, Reier PJ, Fessler RG et al. Feasibility and safety of neural tissue transplantation in patients with syringomyelia. J Neurotrauma 18:911-929, 2001.

124. Rossignol S, Chau C, Brustein E, Belanger M, Barbeau H, Drew T. Locomotor capacities after complete and partial lesions of the spinal cord. Acta Neurobiol Exp (Wars) 56:449-463, 1996.

125. Loy DN, Magnuson DS, Zhang YP et al. Functional redundancy of ventral spinal locomotor pathways. J Neurosci 22:315-323, 2002.

126. Loy DN, Talbott JF, Onifer SM et al. Both dorsal and ventral spinal cord pathways contribute to overground locomotion in the adult rat. Exp Neurol 177:575-580, 2002.

127. Schrimsher GW, Reier PJ. Forelimb motor performance following cervical spinal cord contusion injury in the rat. Exp Neurol 117:287-98, 1992.

128. Schrimsher GW, Reier PJ. Forelimb motor performance following dorsal column, dorsolateral funiculi, or ventrolateral funiculi lesions of the cervical spinal cord in the rat. Exp Neurol 120: 264-76, 1993.

129. Alstermark B, Gorska T, Lundberg A, Pettersson LG. Integration in descending motor pathways controlling the forelimb in the cat. 16. Visually guided switching of target-reaching. Exp Brain Res 80:1-11, 1990.

130. Alstermark B, Isa T, Tantisira B. Projection from excitatory C3-C4 propriospinal neurones to spinocerebellar and spinoreticular neurones in the C6-Th1 segments of the cat. Neurosci Res 8:124-130, 1990.

131. Alstermark B, Isa T, Tantisira B. Integration in descending motor pathways controlling the forelimb in the cat. 18. Morphology, axonal projection and termination of collaterals from c3-c4 propriospinal neurones in the segment of origin. Exp Brain Res 84:561-568, 1991.

132. Sladek JR Jr, Gash DM. Neural transplants: development and function, pp 4-5. New York: Plenum, 1984.

133. Woolsey D, Minckler J, Rezende N, Klemme R. Human spinal cord transplant. Exp Med Surg II:93-102, 1944.

134. Tuszynski MH, Conner J, Blesch A, Smith D, Merrill DA, Vahlsing HL. New strategies in neural repair. Prog Brain Res 138: 401-409, 2002.

135. Plant GW, Ramon-Cueto A, Bunge MB. Transplantation of Schwann cells and ensheathing glia to improve regeneration in adult spinal cord. In: Axonal regeneration in the central nervous system (Ingoglia NA, Murray M, eds), pp 529-561. New York: Marcel Dekker, Inc., 2001.

136. Gauthier P, Rega P, Lammari-Barreault N, Polentes J. Functional reconnections established by central respiratory neurons regenerating axons into a nerve graft bridging the respiratory centers to the cervical spinal cord. J Neurosci Res 70:65-81, 2002.

137. Guénard V, Xu XM, Bunge MB. The use of Schwann cell transplantation to foster central nervous system repair. Neurosciences 5:401-411, 1993.

138. Bray GM, Rasminsky M, Aguayo AJ. Interactions between axons and their sheath cells. Annu Rev Neurosci 4:127-162, 1981.

139. Hall SM. The Schwann cell a reappraisal of its role in the peripheral nervous system. Neuropathol Appl Neurobiol 4:165-176, 1978.

140. Bray GM, Villegas-Perez MP, Vidal-Sanz M, Aguayo AJ. The use of peripheral nerve grafts to enhance neuronal survival, promote growth and permit terminal reconnections in the central nervous system of adult rats. J Exp Biol 132:5-19, 1987.

141. Aguayo AJ, David S, Richardson P, Bray GM. Axonal elongation in peripheral and central nervous system transplants. Adv Cell Neurobiol 3:215-234, 1982.

142. Bunge MB. Bridging areas of injury in the spinal cord. Neuroscientist 7:325-339, 2001.

143. Morrissey TK, Bunge RP, Kleitman N. Human Schwann cells in vitro. I. Failure to differentiate and support neuronal health under co-culture conditions that promote full function of rodent cells. J Neurobiol 28:171-189, 1995.

144. Morrissey TK, Kleitman N, Bunge RP. Human Schwann cells in vitro. II. Myelination of sensory axons following extensive purification and heregulin-induced expansion. J Neurobiol 28:190201, 1995.

145. Jones LL, Oudega M, Bunge MB, Tuszynski MH. Neurotrophic factors, cellular bridges and gene therapy for spinal cord injury. J Physiol (Lond) 533:83-89, 2001.

146. Blits B, Boer GJ, Verhaagen J. Pharmacological, cell, and gene therapy strategies to promote spinal cord regeneration. Cell Transplant 11:593-613, 2002.

147. Tuszynski MH, Weidner N, McCormack M, Miller I, Powell H, Conner J. Grafts of genetically modified Schwann cells to the spinal cord survival, axon growth, and myelination. Cell Transplant 7:187-196, 1998.

148. Kao CC. Comparison of healing process in transected spinal cords grafted with autogenous brain tissue, sciatic nerve, and nodose ganglion. Exp Neurol 44:424-439, 1974.

149. Wrathall JR, Kapoor V, Kao CC. Observation of cultured peripheral non-neuronal cells implanted into the transected spinal cord. Acta Neuropathol (Berl) 64:203-212, 1984.

150. Wrathall JR, Rigamonti DD, Braford MR, Kao CC. Reconstruction of the contused cat spinal cord by the delayed nerve graft technique and cultured peripheral non-neuronal cells. Acta Neuropathol (Berl) 57:59-69, 1982.

151. Bunge MB. Transplantation of purified populations of Schwann cells into lesioned adult rat spinal cord. J Neurol 242:S36-S39, 1994.

152. Guest JD, Rao A, Olson L, Bunge MB, Bunge RP. The ability of human Schwann cell grafts to promote regeneration in the transected nude rat spinal cord. Exp Neurol 148:502-522, 1997.

153. Li Y, Raisman G. Schwann cells induce sprouting in motor and sensory axons in the adult rat spinal cord. $J$ Neurosci 14:4050 4063, 1994.

154. Li Y, Raisman G. Integration of transplanted cultured Schwann cells into the long myelinated fiber tracts of the adult spinal cord. Exp Neurol 145:397-411, 1997.

155. Martin D, Schoenen J, Delree P, Leprince P, Rogister B, Moonen G. Grafts of syngenic cultured, adult dorsal root ganglion-derived Schwann cells to the injured spinal cord of adult rats preliminary morphological studies. Neurosci Lett 124:44-48, 1991.

156. Martin D, Robe P, Franzen R et al. Effects of Schwann cell transplantation in a contusion model of rat spinal cord injury. J Neurosci Res 45:588-597, 1996.

157. Oudega M, Xu XM, Guenard V, Kleitman N, Bunge MB. A combination of insulin-like growth factor-I and platelet-derived growth factor enhances myelination but diminishes axonal regen- 
eration into Schwann cell grafts in the adult rat spinal cord. Glia 19:247-258, 1997.

158. Paino CL, Bunge MB. Induction of axon growth into Schwann cell implants grafted into lesioned adult rat spinal cord. Exp Neurol 114:254-257, 1991.

159. Paino CL, Fernandez-Valle C, Bates ML, Bunge MB. Regrowth of axons in lesioned adult rat spinal cord promotion by implants of cultured Schwann cells. J Neurocytol 23:433-452, 1994.

160. Raisman G. Use of Schwann cells to induce repair of adult CNS tracts. Rev Neurol (Paris) 153:521-525, 1997.

161. Houlé JD, Wright JW, Ziegler MK. After spinal cord injury, chronically injured neurons retain the potential for axonal regeneration. In: Neural transplantation, CNS neuronal injury, and regeneration (Marwah J, Teitelbaum $\mathrm{H}$, Prasad KN, eds), pp 103-118. Boca Raton, FL: CRC, 1994.

162. Houlé JD. Demonstration of the potential for chronically injured neurons to regenerate axons into intraspinal peripheral nerve grafts. Exp Neurol 113:1-9, 1991.

163. Bruce JH, Norenberg MD, Kraydieh S, Puckett W, Marcillo A, Dietrich D. Schwannosis: role of gliosis and proteoglycan in human spinal cord injury. $J$ Neurotrauma 17:781-788, 2000.

164. Kao CC, Sampirisi-Aprile F. Late surgery for thoracolumbar injury with paraplegia. International Congress of Neurological Surgery 8:109, 1985.

165. Campos L, Meng Z, Hu G, Chiu DT, Ambron RT, Martin JH. Engineering novel spinal circuits to promote recovery after spinal injury. J Neurosci 24:2090-2101, 2004.

166. Barros TE, Oliveria R, Barros EMK et al. The use of peripheral nerve bridges to spinal cord injury. Proceedings of the 29th Annual ASIA Scientific Meeting, Miami, 2003. J Spinal Cord Med 26 [Suppl 1]:S11-S48

167. Cheng H, Cao Y, Olson L. Spinal cord repair in adult paraplegic rats partial restoration of hind limb function. Science 273:510 513, 1996.

168. Cheng H, Almström S, Olson L. Fibrin glue used as an adhesive agent in CNS tissues. J Neural Transplant Plast 5:233-243, 1995.

169. Cheng H, Olson L. A new surgical technique that allows proximodistal regeneration of 5-HT fibers after complete transection of the rat spinal cord. Exp Neurol 136:149-161, 1995.

170. Decherchi P, Lammari-Barreault N, Gauthier P. Regeneration of respiratory pathways within spinal peripheral nerve grafts. Exp Neurol 137:1-14, 1996.

171. Aguayo AJ, Bray GM, Rasminsky MM, Zwimpfer T, Carter D, Vidal-Sanz M. Synaptic connections made by axons regenerating in the central nervous system of adult mammals. J Exp Biol 153:199-224, 1990.

172. Levi AD, Dancausse H, Li X, Duncan S, Horkey L, Oliviera M. Peripheral nerve grafts promoting central nervous system regeneration after spinal cord injury in the primate. J Neurosurg 96: 197-205, 2002.

173. Liuzzi FJ, Lasek RJ. Astrocytes block axonal regeneration in mammals by activating the physiological stop pathway. Science 237:642-645, 1987.

174. Pindzola RR, Doller C, Silver J. Putative inhibitory extracellular matrix molecules at the dorsal root entry zone of the spinal cord during development and after root and sciatic nerve lesions. Dev Biol 156:34-48, 1993.

175. Reier PJ, Houlé JD. The glial scar: its bearing on axonal elongation and transplantation approaches to CNS repair. In: Physiologic basis for functional recovery in neurological disease (Waxman SG, ed), pp 87-138. New York: Raven Press, 1988.

176. Reier PJ. Gliosis following CNS injury: its microanatomy and effects on axonal elongation. In: Astrocytes: cell biology and pathology of astrocytes (Fedoroff S, Vernadakis A, eds), Vol 3, pp 263-324. Orlando: Academic Press, 1986.

177. Lee YS, Hsiao I, Lin VW. Peripheral nerve grafts and aFGF restore partial hindlimb function in adult paraplegic rats. $J$ Neurotrauma 19:1203-1216, 2002.

178. Richardson PM, McGuinness UM, Aguayo AJ. Peripheral nerve autografts to the rat spinal cord studies with axonal tracing methods. Brain Res 237:147-162, 1982.

179. Franklin RJ. Remyelination by transplanted olfactory ensheathing cells. Anat Rec 271B:71-76, 2003.
180. Baron-Van Evercooren A, Clerin-Duhamel E, Lapie P, Gansmuller A, Lachapelle F, Gumpel M. The fate of schwann cells transplanted in the brain during development. Dev Neurosci 14:73-84, 1992.

181. Franklin RJ, Blakemore WF. Requirements for Schwann cell migration within CNS environments a viewpoint. Int J Dev Neurosci 11:641-649, 1993.

182. Reier PJ, Stensaas LJ, Guth L. The astrocytic scar as an impediment to regeneration in the central nervous system. In: Spinal cord reconstruction (Kao CC, Bunge RP, Reier PJ, eds), pp 163 196. New York: Raven Press, 1983.

183. Boyd JG, Skihar V, Kawaja M, Doucette R. Olfactory ensheathing cells: historical perspective and therapeutic potential. Anat Rec 271B:49-60, 2003.

184. Plant GW, Bates ML, Bunge MB. Inhibitory proteoglycan immunoreactivity is higher at the caudal than the rostral Schwann cell graft-transected spinal cord interface. Mol Cell Neurosci 17: 471-487, 2001

185. Bradbury EJ, Moon LD, Popat RJ et al. Chondroitinase ABC promotes functional recovery after spinal cord injury. Nature 416:636-640, 2002.

186. Silver J, Miller JH. Regeneration beyond the glial scar. Nat Rev Neurosci 5:146-156, 2004.

187. Davies SJ, Fitch MT, Memberg SP, Hall AK, Raisman G, Silver J. Regeneration of adult axons in white matter tracts of the central nervous system. Nature 390:680-683, 1997.

188. Filbin MT. Myelin-associated inhibitors of axonal regeneration in the adult mammalian CNS. Nat Rev Neurosci 4:703-713, 2003.

189. McKerracher L. Spinal cord repair strategies to promote axon regeneration. Neurobiol Dis 8:11-18, 2001.

190. Menei P, Montero-Menei C, Whittemore SR, Bunge RP, Bunge MB. Schwann cells genetically modified to secrete human BDNF promote enhanced axonal regrowth across transected adult rat spinal cord. Eur J Neurosci 10:607-621, 1998.

191. Xu XM, Zhang SX, Li H, Aebischer P, Bunge MB. Regrowth of axons into the distal spinal cord through a Schwann-cell-seeded mini-channel implanted into hemisected adult rat spinal cord. Eur J Neurosci 11:1723-1740, 1999.

192. Bamber NI, Li H, Lu X, Oudega M, Aebischer P, Xu XM. Neurotrophins BDNF and NT-3 promote axonal re-entry into the distal host spinal cord through Schwann cell-seeded mini-channels. Eur J Neurosci 13:257-268, 2001.

193. Pearse DD, Pereira FC, Marcillo AE et al. cAMP and Schwann cells promote axonal growth and functional recovery after spinal cord injury. Nat Med 10: 610-616, 2004.

194. Barnett SC. Olfactory ensheathing cells: unique glial cell types? $J$ Neurotrauma 21:375-382, 2004.

195. Franklin RJ. Obtaining olfactory ensheathing cells from extracranial sources a step closer to clinical transplant-mediated repair of the CNS? Brain 125:2-3, 2002.

196. Doucette R. Olfactory ensheathing cells potential for glial cell transplantation into areas of CNS injury. Histol Histopathol 10 503-507, 1995.

197. Ramon-Cueto A, Avila J. Olfactory ensheathing glia properties and function. Brain Res Bull 46:175-187, 1998.

198. Franklin RJ, Barnett SC. Olfactory ensheathing cells and CNS regeneration: the sweet smell of success? Neuron 28:15-18, 2000.

199. Lakatos A, Franklin RJ, Barnett SC. Olfactory ensheathing cells and Schwann cells differ in their in vitro interactions with astrocytes. Glia 32:214-225, 2000.

200. Lu J, Ashwell K. Olfactory ensheathing cells their potential use for repairing the injured spinal cord. Spine 27:887-892, 2002.

201. Lu J, Feron F, Ho SM, kay-Sim A, Waite PM. Transplantation of nasal olfactory tissue promotes partial recovery in paraplegic adult rats. Brain Res 889:344-57, 2001.

202. Ramon-Cueto A. Olfactory ensheathing glia transplantation into the injured spinal cord. Prog Brain Res 128:265-72, 2000.

203. Raisman G. Olfactory ensheathing cells - another miracle cure for spinal cord injury? Nat Rev Neurosci 2:369-75, 2001.

204. Li Y, Field PM, Raisman G. Regeneration of adult rat corticospinal axons induced by transplanted olfactory ensheathing cells. J Neurosci 18:10514-10524, 1998. 
205. Li Y, Field PM, Raisman G. Repair of adult rat corticospinal tract by transplants of olfactory ensheathing cells. Science 277:20002002, 1997.

206. Ramon-Cueto A, Plant GW, Avila J, Bunge MB. Long-distance axonal regeneration in the transected adult rat spinal cord is promoted by olfactory ensheathing glia transplants. J Neurosci 18:3803-3815, 1998.

207. Ramon-Cueto A, Cordero MI, Santos-Benito FF, Avila J. Functional recovery of paraplegic rats and motor axon regeneration in their spinal cords by olfactory ensheathing glia. Neuron 25:425435, 2000.

208. Lu J, Feron F, kay-Sim A, Waite PM. Olfactory ensheathing cells promote locomotor recovery after delayed transplantation into transected spinal cord. Brain 125:14-21, 2002.

209a. Li Y, Decherchi P, Raisman G. Transplantation of olfactory ensheathing cells into spinal cord lesions restores breathing and climbing. J Neurosci 23:727-731, 2003.

209b. Polentes J, Stamegna JC, Nieto-Sampedro M, Gauthier P. Phrenic rehabilitation and diaphragm recovery after cervical injury and transplantation of olfactory ensheathing cells. Neurobiol Dis 16:638-653, 2004.

210. Nieto-Sampedro M. Central nervous system lesions that can and those that cannot be repaired with the help of olfactory bulb ensheathing cell transplants. Neurochem Res 28:1659-1676, 2003.

211. Imaizumi T, Lankford KL, Kocsis JD. Transplantation of olfactory ensheathing cells or Schwann cells restores rapid and secure conduction across the transected spinal cord. Brain Res 854:70$78,2000$.

212. Imaizumi T, Lankford KL, Burton WV, Fodor WL, Kocsis JD. Xenotransplantation of transgenic pig olfactory ensheathing cells promotes axonal regeneration in rat spinal cord. Nat Biotechnol 18:949-953, 2000.

213. Lakatos A, Barnett SC, Franklin RJ. Olfactory ensheathing cells induce less host astrocyte response and chondroitin sulphate proteoglycan expression than Schwann cells following transplantation into adult CNS white matter. Exp Neurol 184:237-246, 2003.

214. Ramer LM, Au E, Richter MW, Liu J, Tetzlaff W, Roskams AJ. Peripheral olfactory ensheathing cells reduce scar and cavity formation and promote regeneration after spinal cord injury. J Comp Neurol 473:1-15, 2004.

215. Verdu E, Garcia-Alias G, Fores J et al. Effects of ensheathing cells transplanted into photochemically damaged spinal cord. NeuroReport 12:2303-2309, 2001.

216. Takami T, Oudega M, Bates ML, Wood PM, Kleitman N, Bunge MB. Schwann cell but not olfactory ensheathing glia transplants improve hindlimb locomotor performance in the moderately contused adult rat thoracic spinal cord. J Neurosci 22:6670-6681, 2002.

217. Plant GW, Currier PF, Cuervo EP et al. Purified adult ensheathing glia fail to myelinate axons under culture conditions that enable Schwann cells to form myelin. J Neurosci 22:6083-6091, 2002.

218. Senior K. Olfactory ensheathing cells to be used in spinal-cord repair trial. Lancet Neurol 1:269, 2002.

219. Huang H, Chen L, Wang $\mathrm{H}$ et al. Influence of patients' age on functional recovery after transplantation of olfactory ensheathing cells into injured spinal cord injury. Chin Med J (Engl) 116: 1488-1491, 2003.

220. Plant GW, Christensen CL, Oudega M, Bunge MB. Delayed transplantation of olfactory ensheathing glia promotes sparing/ regeneration of supraspinal axons in the contused adult rat spinal cord. J Neurotrauma 20:1-16, 2003.

221. Pittenger MF, Mackay AM, Beck SC et al. Multilineage potential of adult human mesenchymal stem cells. Science 284:143-147, 1999.

222. Lee J, Kuroda S, Shichinohe $\mathrm{H}$ et al. Migration and differentiation of nuclear fluorescence-labeled bone marrow stromal cells after transplantation into cerebral infarct and spinal cord injury in mice. Neuropathology 23:169-180, 2003.

223. Woodbury D, Schwarz EJ, Prockop DJ, Black IB. Adult rat and human bone marrow stromal cells differentiate into neurons. J Neurosci Res 61:364-370, 2000.

224. Brazelton TR, Rossi FM, Keshet GI, Blau HM. From marrow to brain expression of neuronal phenotypes in adult mice. Science 290:1775-1779, 2000.

225. Mezey E, Chandross KJ, Harta G, Maki RA, McKercher SR Turning blood into brain cells bearing neuronal antigens generated in vivo from bone marrow. Science 290:1779-1782, 2000.

226a. Castro RF, Jackson KA, Goodell MA, Robertson CS, Liu H, Shine HD. Failure of bone marrow cells to transdifferentiate into neural cells in vivo. Science 297:1299, 2002.

226b. Terada N, Hamazaki T, Oka M et al. Bone marrow cells adopt the phenotype of other cells by spontaneous cell fusion. Nature 416:542-545, 2002.

227. Camargo FD, Chambers SM, Goodell MA. Stem cell plasticity from transdifferentiation to macrophage fusion. Cell Prolif 37: 55-65, 2004.

228. Hofstetter CP, Schwarz EJ, Hess D et al. Marrow stromal cells form guiding strands in the injured spinal cord and promote recovery. Proc Natl Acad Sci USA 99:2199-2204, 2002.

229. Svendsen CN, Bhattacharyya A, Tai YT. Neurons from stem cells preventing an identity crisis. Nat Rev Neurosci 2:831-834, 2001.

230. Cogle CR, Yachnis AT, Laywell ED et al. Bone marrow transdifferentiation in brain after transplantation a retrospective study. Lancet 363:1432-1437, 2004.

231. Jendelova P, Herynek V, Urdzikova L et al. Magnetic resonance tracking of transplanted bone marrow and embryonic stem cells labeled by iron oxide nanoparticles in rat brain and spinal cord. J Neurosci Res 76:232-243, 2004.

232. Azizi SA, Stokes D, Augelli BJ, DiGirolamo C, Prockop DJ. Engraftment and migration of human bone marrow stromal cells implanted in the brains of albino rats-similarities to astrocyte grafts. Proc Natl Acad Sci USA 95:3908-3913, 1998.

233. Chopp M, Zhang XH, Li Y et al. Spinal cord injury in rat treatment with bone marrow stromal cell transplantation. NeuroReport 11:3001-3005, 2000.

234. Wu S, Suzuki Y, Ejiri Y et al. Bone marrow stromal cells enhance differentiation of cocultured neurosphere cells and promote regeneration of injured spinal cord. J Neurosci Res 72:343-351, 2003.

235. Zurita M, Vaquero J. Functional recovery in chronic paraplegia after bone marrow stromal cells transplantation. NeuroReport 15:1105-1108, 2004.

236. Syková E, Jendelová P, Glogarová K, Urzilová L, Herynek V, Hajek M. Bone marrow stromal cells - a promising tool for therapy of brain and spinal cord injury. Exp Neurol 187:220, 2004.

237. Hirschberg DL, Schwartz M. Macrophage recruitment to acutely injured central nervous system is inhibited by a resident factor a basis for an immune-brain barrier. J Neuroimmunol 61:89-96, 1995.

238. Lazarov-Spiegler O, Solomon AS, Zeev-Brann AB, Hirschberg DL, Lavie V, Schwartz M. Transplantation of activated macrophages overcomes central nervous system regrowth failure. FASEB J 10:1296-1302, 1996.

239. Lazarov-Spiegler O, Solomon AS, Schwartz M. Peripheral nervestimulated macrophages simulate a peripheral nerve-like regenerative response in rat transected optic nerve. Glia 24:329-337, 1998.

240. Rapalino O, Lazarov-Spiegler O, Agranov E et al. Implantation of stimulated homologous macrophages results in partial recovery of paraplegic rats. Nat Med 4:814-821, 1998.

241. Lammertse D. Clinical trials in spinal cord injury: the Proneuron activated macrophage trial. Proceedings of the 49th Annual Conference of the American Paraplegia Society, 2003.

242. Bomstein Y, Marder JB, Vitner K et al. Features of skin-coincubated macrophages that promote recovery from spinal cord injury. J Neuroimmunol 142:10-16, 2003.

243. Popovich PG, Guan Z, McGaughy V, Fisher L, Hickey WF, Basso DM. The neuropathological and behavioral consequences of intraspinal microglial/macrophage activation. $J$ Neuropathol Exp Neurol 61:623-633, 2002.

244. Popovich PG, Guan Z, Wei P, Huitinga I, van RN, Stokes BT. Depletion of hematogenous macrophages promotes partial hindlimb recovery and neuroanatomical repair after experimental spinal cord injury. Exp Neurol 158:351-365, 1999. 
245. Blight AR. Effect of 4-aminopyridine on axonal conductionblock in chronic spinal cord injury. Brain Res Bull 22:47-52, 1989.

246. Blight AR, Toombs JP, Bauer MS, Widmer WR. The effects of 4-aminopyridine on neurological deficits in chronic cases of traumatic spinal cord injury in dogs a phase I clinical trial. $J$ Neurotrauma 8:103-118, 1991.

247. Shi R, Kelly TM, Blight AR. Conduction block in acute and chronic spinal cord injury different dose-response characteristics for reversal by 4-aminopyridine. Exp Neurol 148:495-501, 1997.

248. Waxman SG. Aminopyridines and the treatment of spinal-cord injury. J Neurotrauma 10:19-24, 1993.

249. Kocsis JD. Restoration of function by glial cell transplantation into demyelinated spinal cord. J Neurotrauma 16:695-703, 1999.

250. Duncan ID, Grever WE, Zhang SC. Repair of myelin disease strategies and progress in animal models. Mol Med Today 3:554561, 1997.

251. Kohama I, Lankford KL, Preiningerova J, White FA, Vollmer TL, Kocsis JD. Transplantation of cryopreserved adult human Schwann cells enhances axonal conduction in demyelinated spinal cord. J Neurosci 21:944-950, 2001.

252. Tuszynski MH, Weidner N, McCormack M, Miller I, Powell H, Conner J. Grafts of genetically modified Schwann cells to the spinal cord: Survival, axon growth, and myelination. Cell Transplant 1998;7:187-96.

253. Kato T, Honmou O, Uede T, Hashi K, Kocsis JD. Transplantation of human olfactory ensheathing cells elicits remyelination of demyelinated rat spinal cord. Glia 30:209-218, 2000.

254. Franklin RJ. Remyelination of the demyelinated CNS the case for and against transplantation of central, peripheral and olfactory glia. Brain Res Bull 57:827-832, 2002.

255. Akiyama Y, Radtke C, Honmou O, Kocsis JD. Remyelination of the spinal cord following intravenous delivery of bone marrow cells. Glia 39:229-236, 2002.

256. Rosenbluth J, Schiff R, Liang WL, Menna G, Young W. Xenotransplantation of transgenic oligodendrocyte-lineage cells into spinal cord-injured adult rats. Exp Neurol 147:172-182, 1997.

257. Smith PM, Blakemore WF. Porcine neural progenitors require commitment to the oligodendrocyte lineage prior to transplantation in order to achieve significant remyelination of demyelinated lesions in the adult CNS. Eur J Neurosci 12:2414-2424, 2000.

258. Blakemore WF, Gilson JM, Crang AJ. Transplanted glial cells migrate over a greater distance and remyelinate demyelinated lesions more rapidly than endogenous remyelinating cells. $J$ Neurosci Res 61:288-294, 2000.

259. Vignais L, Nait OB, Mellouk F et al. Transplantation of oligodendrocyte precursors in the adult demyelinated spinal cord migration and remyelination. Int J Dev Neurosci 11:603-612, 1993.

260. Windrem MS, Nunes MC, Rashbaum WK et al. Fetal and adult human oligodendrocyte progenitor cell isolates myelinate the congenitally dysmyelinated brain. Nat Med 10:93-97, 2004.

261. Zhang SC, Wernig M, Duncan ID, Brustle O, Thomson JA. In vitro differentiation of transplantable neural precursors from human embryonic stem cells. Nat Biotechnol 19:1129-1133, 2001.

262. Herrera J, Yang H, Zhang SC et al. Embryonic-derived glialrestricted precursor cells (GRP cells) can differentiate into astrocytes and oligodendrocytes in vivo. Exp Neurol 171:11-21, 2001.

263. Liu S, Qu Y, Stewart TJ et al. Embryonic stem cells differentiate into oligodendrocytes and myelinate in culture and after spinal cord transplantation. Proc Natl Acad Sci USA 97:6126-6131, 2000.

264. Brustle O, Jones KN, Learish RD et al. Embryonic stem cellderived glial precursors a source of myelinating transplants. Science 285:754-756, 1999.

265. McDonald JW, Liu XZ, Qu Y et al. Transplanted embryonic stem cells survive, differentiate and promote recovery in injured rat spinal cord. Nat Med 5:1410-1412, 1999.

266. Kocsis JD, Akiyama Y, Radtke C. Neural precursors as a cell source to repair the demyelinated spinal cord. $J$ Neurotrauma 21:441-449, 2004.

267. Akiyama Y, Honmou O, Kato T, Uede T, Hashi K, Kocsis JD. Transplantation of clonal neural precursor cells derived from adult human brain establishes functional peripheral myelin in the rat spinal cord. Exp Neurol 167:27-39, 2001.

268. Zhang SC, Ge B, Duncan ID. Adult brain retains the potential to generate oligodendroglial progenitors with extensive myelination capacity. Proc Natl Acad Sci USA 96:4089-4094, 1999.

269. Bulte JW, Douglas T, Witwer B et al. Monitoring stem cell therapy in vivo using magnetodendrimers as a new class of cellular MR contrast agents. Acad Radiol 9 [Suppl 2]:S332-S335, 2002.

270. Zhang SC, Goetz BD, Duncan ID. Suppression of activated microglia promotes survival and function of transplanted oligodendroglial progenitors. Glia 41:191-198, 2003.

271. Radtke C, Akiyama Y, Brokaw J et al. Remyelination of the nonhuman primate spinal cord by transplantation of $\mathrm{H}$-transferase transgenic adult pig olfactory ensheathing cells. FASEB $J 18$ : 335-337, 2004.

272. Bjorklund A, Dunnett SB, Brundin P et al. Neural transplantation for the treatment of Parkinson's disease. Lancet Neurol 2:437445, 2003.

273. Thompson FJ, Reier PJ, Uthman B et al. Neurophysiological assessment of the feasibility and safety of neural tissue transplantation in patients with syringomyelia. $J$ Neurotrauma 18:931945, 2001.

274. Falci S, Holtz A, Akesson E et al. Obliteration of a posttraumatic spinal cord cyst with solid human embryonic spinal cord grafts first clinical attempt. J Neurotrauma 14:875-884, 1997.

275. Seiger A, Holtz A, Akesson E et al. Fetal spinal cord grafting in man. J Neurol Rehab 12:198-199, 1998.

276. Blagodatskii MD, Sufianov AA, Larionov SN, Kibort RV, Seminskii IZ, Manokhin PA. The transplantation of embryonic nerve tissue in syringomyelia: initial clinical experience. Zh Vopr Neirokhir Im N N Burdenko (1):27-29, 1994.

277. Reier PJ, Stokes BT, Thompson FJ, Anderson DK. Fetal cell grafts into resection and contusion/compression injuries of the rat and cat spinal cord. Exp Neurol 115:177-188, 1992.

278. Reier PJ, Anderson DK, Schrimsher GW et al. Neural cell grafting: anatomical and functional repair of the spinal cord. In: The neurobiology of central nervous system trauma (Salzman SK, Faden AI, eds), pp 288-311. New York: Oxford University Press, 1994.

279. Reier PJ, Golder FJ, Bolser DC et al. Gray matter repair in the cervical spinal cord. Prog Brain Res 137:49-70, 2002.

280. Tessler A. Intraspinal transplants. Ann Neurol 29:115-123, 1991.

281. Bregman BS, Coumans JV, Dai HN et al. Transplants and neurotrophic factors increase regeneration and recovery of function after spinal cord injury. Prog Brain Res 137:257-273, 2002.

282. Wirth ED III, Theele DP, Mareci TH, Anderson DK, Reier PJ Dynamic assessment of intraspinal neural graft survival using magnetic resonance imaging. Exp Neurol 136:64-72, 1995.

283. Wirth ED III, Theele DP, Mareci TH, Anderson DK, Brown SA, Reier PJ. In vivo magnetic resonance imaging of fetal cat neural tissue transplants in the adult cat spinal cord. $J$ Neurosurg 76: 261-274, 1992.

284. Akesson E, Markling L, Kjaeldgaard A, Falci S, Ringden O. MHC antigen expression in human first trimester spinal cord with implications for clinical transplantation procedures. J Neuroimmunol 111:210-214, 2000.

285. Schnell L, Fearn S, Klassen H, Schwab ME, Perry VH. Acute inflammatory responses to mechanical lesions in the CNS differences between brain and spinal cord. Eur J Neurosci 11:36483658, 1999.

286. Popovich PG, Wei P, Stokes BT. Cellular inflammatory response after spinal cord injury in Sprague-Dawley and Lewis rats. J Comp Neurol 377:443-464, 1997.

287. Hayes KC, Hull TC, Delaney GA et al. Elevated serum titers of proinflammatory cytokines and CNS autoantibodies in patients with chronic spinal cord injury. J Neurotrauma 19:753-761, 2002.

288. Theele DP, Schrimsher GW, Reier PJ. Comparison of the growth and fate of fetal spinal iso- and allografts in the adult rat injured spinal cord. Exp Neurol 142:128-143, 1996.

289. Anderson DK, Reier PJ, Wirth ED III, Theele DP, Brown SA. 
Transplants of fetal CNS grafts in chronic compression lesions of the adult cat spinal cord. Restor Neurol Neurosci 2:309-325, 1991.

290. Lindvall O, Sawle G, Widner H et al. Evidence for long-term survival and function of dopaminergic grafts in progressive Parkinson's disease. Ann Neurol 35:172-180, 1994.

291. Kordower JH, Freeman TB, Snow BJ et al. Neuropathological evidence of graft survival and striatal reinnervation after the transplantation of fetal mesencephalic tissue in a patient with Parkinson's disease. N Engl J Med 332:1118-1124, 1995.

292. Stokes BT, Reier PJ. Fetal grafts alter chronic behavioral outcome after contusion damage to the adult rat spinal cord. Exp Neurol 116:1-12, 1992.

293. Kunkel-Bagden E, Bregman BS. Spinal cord transplants enhance the recovery of locomotor function after spinal cord injury at birth. Exp Brain Res 81:25-34, 1990.

294. Kunkel Bagden E, Dai HN, Bregman BS. Recovery of function after spinal cord hemisection in newborn and adult rats differential effects on reflex and locomotor function. Exp Neurol 116: 40-51, 1992.

295. Diener PS, Bregman BS. Fetal spinal cord transplants support the development of target reaching and coordinated postural adjustments after neonatal cervical spinal cord injury. J Neurosci 18: 763-778, 1998.

296. Ribotta MG, Provencher J, Feraboli-Lohnherr D, Rossignol S, Privat A, Orsal D. Activation of locomotion in adult chronic spinal rats is achieved by transplantation of embryonic raphe cells reinnervating a precise lumbar level. J Neurosci 20:5144-5152, 2000.

297. Howland DR, Bregman BS, Tessler A, Goldberger ME. Transplants enhance locomotion in neonatal kittens whose spinal cords are transected a behavioral and anatomical study. Exp Neurol 135:123-145, 1995.

298. Anderson DK, Howland DR, Reier PJ. Fetal neural grafts and repair of the injured spinal cord. Brain Pathol 5:451-457, 1995.

299. Howland DR, Reier PJ, Anderson DK. Intraspinal transplantation of fetal tissue: therapeutic potential for spinal cord repair. In: Neurotrauma: a comprehensive textbook on head and spinal injury (Narayan RK, Wilberger JE, Povlishock JT, eds), pp 15071520. New York: McGraw-Hill, Inc., 1995.

300. Coumans JV, Lin TT, Dai HN et al. Axonal regeneration and functional recovery after complete spinal cord transection in rats by delayed treatment with transplants and neurotrophins. $J$ Neurosci 21:9334-9344, 2001.

301. Nikulina E, Tidwell JL, Dai HN, Bregman BS, Filbin MT. The phosphodiesterase inhibitor rolipram delivered after a spinal cord lesion promotes axonal regeneration and functional recovery. Proc Natl Acad Sci USA 101:8786-8790, 2004.

302. Bose P, Parmer R, Thompson FJ. Velocity-dependent ankle torque in rats after contusion injury of the midthoracic spinal cord time course. J Neurotrauma 19:1231-1249, 2002.

303. Thompson FJ, Reier PJ, Parmer R, Lucas CC. Inhibitory control of reflex excitability following contusion injury and neural tissue transplantation. In: Advances in neurology (Seil FJ, ed), Vol 59, pp 175-184. New York: Raven Press, 1993.

304. Thompson FJ, Parmer R, Reier PJ, Wang DC, Bose P. Scientific basis of spasticity insights from a laboratory model. $J$ Child Neurol 16:2-9, 2001.

305. Thompson FJ, Reier PJ, Lucas CC, Parmer R. Altered patterns of reflex excitability subsequent to contusion injury of the rat spinal cord. J Neurophysiol 68:1473-1486, 1992.

306. Calancie B, Broton JG, Klose KJ, Traad M, Difini J, Ayyar DR. Evidence that alterations in presynaptic inhibition contribute to segmental hypo- and hyperexcitability after spinal cord injury in man. Electroencephalogr Clin Neurophysiol 89:177-186, 1993.

307. Schindler-Ivens S, Shields RK. Low frequency depression of H-reflexes in humans with acute and chronic spinal-cord injury. Exp Brain Res 133:233-241, 2000.

308. Wictorin K, Bjorklund A. Axon outgrowth from grafts of human embryonic spinal cord in the lesioned adult rat spinal cord. $\mathrm{Neu}$ roReport 3:1045-1048, 1992.

309. Giovanini MA, Reier PJ, Eskin TA, Wirth E, Anderson DK. Characteristics of human fetal spinal cord grafts in the adult rat spinal cord influences of lesion and grafting conditions. Exp Neurol 148:523-543, 1997.

310. Giovanini MA, Reier PJ, Eskin TA, Anderson DK. MAP2 expression in the developing human fetal spinal cord and following xenotransplantation. Cell Transplant 6:339-346, 1997.

311. Akesson E, Kjaeldgaard A, Seiger A. Human embryonic spinal cord grafts in adult rat spinal cord cavities survival, growth, and interactions with the host. Exp Neurol 149:262-276, 1998.

312. Falci SP, Lammertse DP, Best L et al. Surgical treatment of posttraumatic cystic and tethered spinal cords. J Spinal Cord Med 22:173-181, 1999.

313. Kromer LF, Björklund A. Intracephalic implants a technique for studying neuronal interactions. Science 204:1117-1119, 1979.

314. Redmond DE Jr. Cellular replacement therapy for Parkinson's disease-where we are today? Neuroscientist 8:457-488, 2002.

315. Velardo MJ, Burger C, Williams PR et al. Patterns of gene expression reveal a temporally orchestrated wound healing response in the injured spinal cord. $J$ Neurosci (in press), 2004.

316. Tobias CA, Shumsky JS, Shibata M et al. Delayed grafting of $\mathrm{BDNF}$ and NT-3 producing fibroblasts into the injured spinal cord stimulates sprouting, partially rescues axotomized red nucleus neurons from loss and atrophy, and provides limited regeneration. Exp Neurol 184:97-113, 2003.

317. Houle JD, Tessler A. Repair of chronic spinal cord injury. Exp Neurol 182:247-260, 2003.

318. Schwartz M, Hauben E. T cell-based therapeutic vaccination for spinal cord injury. Prog Brain Res 137:401-406, 2002.

319. Schwartz M. Protective autoimmunity as a T-cell response to central nervous system trauma prospects for therapeutic vaccines. Prog Neurobiol 65:489-496, 2001.

320. Yoles E, Hauben E, Palgi O et al. Protective autoimmunity is a physiological response to CNS trauma. $J$ Neurosci 21:37403748, 2001.

321. Hauben E, Schwartz M. Therapeutic vaccination for spinal cord injury helping the body to cure itself. Trends Pharmacol Sci 24:7-12, 2003.

322. Hauben E, Agranov E, Gothilf A et al. Posttraumatic therapeutic vaccination with modified myelin self-antigen prevents complete paralysis while avoiding autoimmune disease. J Clin Invest 108: 591-599, 2001

323. Hauben E, Butovsky O, Nevo U et al. Passive or active immunization with myelin basic protein promotes recovery from spinal cord contusion. J Neurosci 20:6421-6430, 2000.

324. Jones TB, Basso DM, Sodhi A et al. Pathological CNS autoimmune disease triggered by traumatic spinal cord injury implications for autoimmune vaccine therapy. $J$ Neurosci 22:2690-2700, 2002.

325. Jones TB, Ankeny DP, Guan Z et al. Passive or active immunization with myelin basic protein impairs neurological function and exacerbates neuropathology after spinal cord injury in rats. $J$ Neurosci 24:3752-3761, 2004.

326. Webb AA, Gowribai K, Muir GD. Fischer (F-344) rats have different morphology, sensorimotor and locomotor abilities compared to Lewis, Long-Evans, Sprague-Dawley and Wistar rats. Behav Brain Res 144:143-156, 2003.

327. Mills CD, Hains BC, Johnson KM, Hulsebosch CE. Strain and model differences in behavioral outcomes after spinal cord injury in rat. J Neurotrauma 18:743-756, 2001.

328. Freeman TB, Vawter DE, Leaverton PE et al. The use of placebo surgery in controlled trials of a cellular-based therapy for Parkinson's disease. N Engl J Med 341:988-992, 1999.

329. Macklin R. The ethical problems with sham surgery in clinical research. N Engl J Med 341:992-996, 1999.

330. Cao QL, Howard RM, Dennison JB, Whittemore SR. Differentiation of engrafted neuronal-restricted precursor cells is inhibited in the traumatically injured spinal cord. Exp Neurol 177:349359, 2002.

331. Cao QL, Zhang YP, Howard RM, Walters WM, Tsoulfas P, Whittemore SR. Pluripotent stem cells engrafted into the normal or lesioned adult rat spinal cord are restricted to a glial lineage. Exp Neurol 167:48-58, 2001. 